\title{
Neurotropic Coronavirus Infections
}

\author{
Stanley Perlman and D. Lori Wheeler
}

\section{Introduction/Classification}

Mouse hepatitis virus (MHV) is a member of the Coronaviridae family in the order Nidovirales. Coronaviruses are classified into one of three antigenic groups with MHV classified as a lineage a betacoronavirus (de Groot et al. 2013) Members of the Coronaviridae family infect a wide range of species including humans, cows, pigs, chickens, dogs, cats, bats, and mice. In addition to causing clinically relevant disease in humans ranging from mild upper respiratory infection (e.g., $\mathrm{HCoV}$ [human coronavirus]OC43 and HCoV-229E, HCoV-NL63, and HCoV-HKU1) to severe acute respiratory syndrome (SARS) and the Middle East Respiratory Syndrome (MERS) (Ksiazek et al. 2003; Peiris et al. 2003a; Zaki et al. 2012), coronavirus infections in cows, chickens, and pigs exact a significant annual economic toll on the livestock industry.

MHV is a natural pathogen of mice that generally is restricted to replication within the gastrointestinal tract (Compton et al. 1993; Homberger et al. 1992). However, there exist several laboratory strains of MHV that have adapted to replicate efficiently in the central nervous system (CNS) of mice and other rodents. Depending on the strain of MHV, virulence and pathology ranges from mild encephalitis with subsequent clearance of the virus and concomitant development of demyelination to rapidly fatal encephalitis. Thus, the neurotropic strains of MHV have proved to be useful systems in which to

\footnotetext{
S. Perlman $(\bowtie) \bullet$ D.L. Wheeler

Interdisciplinary Program in Immunology, University of Iowa, Iowa City, IA, USA

Department of Microbiology, University of Iowa,

BSB 3-712, 51 Newton Road, Iowa City, IA 52242, USA

e-mail: stanley-perlman@uiowa.edu
} 
study processes of virus- and immune-mediated demyelination, virus clearance, and/or persistence in the CNS and the mechanisms of virus evasion of the immune system.

\section{Structure}

Coronaviruses are large (80-120 nM) pseudospherical particles that contain a long, helical nucleocapsid surrounded by an envelope bearing both virus- and host-derived glycoproteins (reviewed in Masters and Perlman 2013). The largest among known RNA viruses, the genome of coronaviruses consists of a single-stranded, positivesense, $5^{\prime}$-capped, and polyadenylated RNA of 30-32 kilobases. The 5' two-thirds of the RNA genome of coronaviruses encodes the replicase-transcriptase machinery and is expressed as two very large open reading frames (ORF), ORF1a and ORF1b. The remainder of the genome encodes the structural proteins emagluttinin-esterase protein (HE), spike glycoprotein (S), envelope protein (E), transmembrane glycoprotein $(\mathrm{M})$, and nucleocapsid protein $(\mathrm{N})$, as well as additional, group-specific accessory proteins (reviewed in Masters 2006). The three MHV ORFs encoding accessory proteins are interspersed within the structural genes and include ORF2a, ORF4, and ORF5a (encode ns2, ns4, and ns5a respectively) (Lai and Cavanagh 1997; Masters and Perlman 2013) (Fig. 1b). These general features of genomic organization are shared among all members of the Coronaviridae family; however, substantial variability exists in the number and type of ORFs expressed in the $3^{\prime}$ region of the genome. Remarkably, there is no obvious homology between the group-specific proteins encoded by different coronaviruses. In fact, in the case of the SARS-CoV, several of these "nonstructural" proteins, including the ORF3a, 7a, 7b proteins, have turned out to be structural (Huang et al. 2006a; Ito et al. 2005; Schaecher et al. 2007).

Several virus-encoded proteins are packaged into the virion, including the nucleocapsid (N), the spike (S) glycoprotein, the envelope (E) protein, and the transmembrane (M) glycoprotein (Fig. 1a). In some strains of MHV and several other group 2 coronaviruses, the envelope also contains a hemagglutinin-esterase (HE) protein. The S protein mediates attachment and fusion with the host cell, is the target for neutralizing antibody and often the cellular immune response, and has been shown to play a pivotal role in pathogenesis. The $\mathrm{N}$ protein is intimately associated with the viral RNA genome, forms the basic structure of the helical nucleocapsid, and has been shown to be involved in several aspects of genome replication (Masters 2006; Masters and Perlman 2013; Shi and Lai 2005). As the most abundant of all structural proteins in the virion, the $M$ protein is known to play a key role in assembly and particle formation through specific interaction with S (Godeke et al. 2000), N (Hurst et al. 2005), and possibly (Baudoux et al. 1998) E proteins. Even though it is relatively underrepresented in the mature virus particle (Yu et al. 1994), the E protein is also believed to play a role in virus assembly, but is not absolutely required for this process (Kuo and Masters 2003). In addition, the E protein forms pentameric bundles within lipid bi-layers that have cation-selective ion channel activity (Wilson et al. 2006). While the function of the HE is not fully understood, this protein possesses esterase activity (Vlasak et al. 1988a), and is not required 


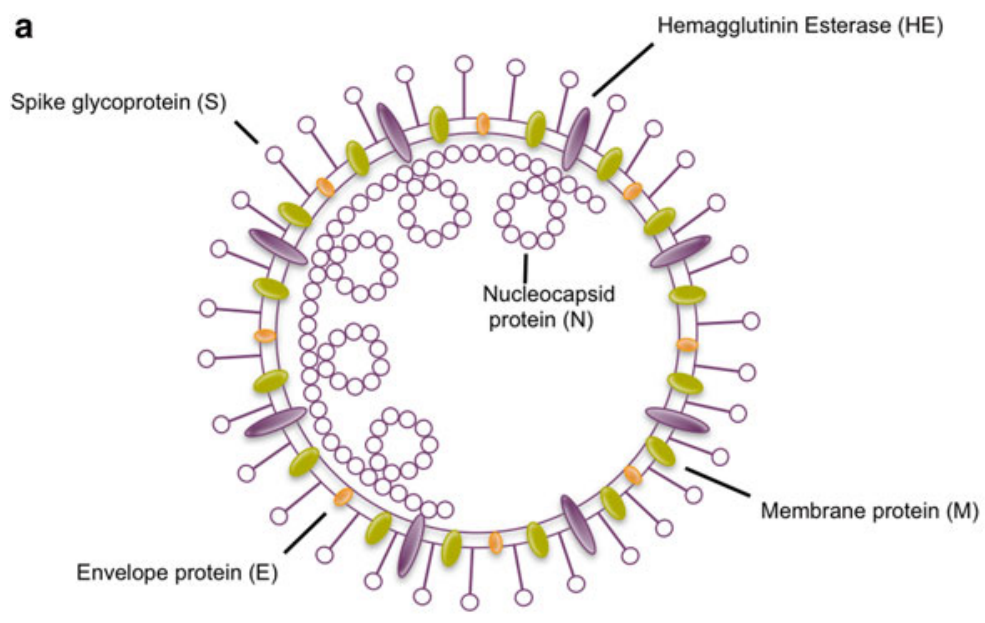

b

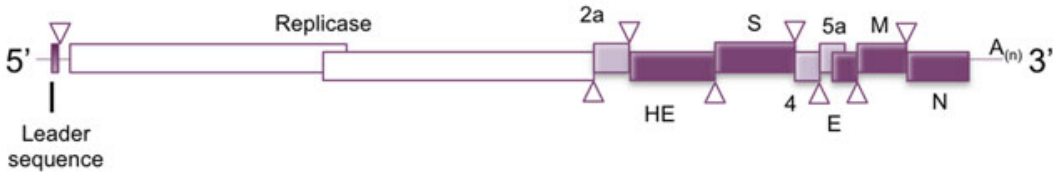

Fig. 1 (a) Structure of the MHV coronavirus virion depicting structural proteins. (b) Schematic representation of the genomic organization of mouse hepatitis virus. Replicase genes, accessory genes, and structural genes are indicated by open, shaded, and solid rectangles, respectively. Open triangles depict the location of transcription-regulating sequences (TRS)

for virus replication in tissue culture cells (de Haan et al. 2002; Schwarz et al. 1990). However, recent evidence suggests that the HE may enhance infectivity and spread of coronaviruses within certain tissues, perhaps by serving as a second receptor-binding protein or by modulating virus release (Kazi et al. 2005).

The coronavirus accessory proteins (Fig. 1b) are not individually required for growth in tissue culture cells (Vlasak et al. 1988a). However, deletion of all accessory genes from MHV attenuates the virus in vitro and in vivo (de Haan et al. 2002). Although deletion of individual $3^{\prime}$ accessory proteins has little effect on virus replication in tissue culture, their conservation within the species suggests that the accessory proteins play important roles in modulating the host immune response or general host cellular processes in vivo. With regard to pathogenesis, some accessory proteins appear dispensable while others (alone or in combination) are critical for replication in the intact animal. For example, deletion of the ORF4 gene in MHV-JHM does not affect lethality (Ontiveros et al. 2003), while mutation or deletion of the ORF2a gene did not affect growth in tissue culture cells but attenuated replication in mice (Schwarz et al. 1990; Sperry et al. 2005). A recent study has shown that ORF2a has $2^{\prime}, 5^{\prime}$-phosphodiesterase activity which prevents the activation of cellular RNase L, thereby preventing the degradation of viral RNA (Zhao et al. 2012). This antagonism of the 
interferon response promotes hepatitis in MHV-A59 infected mice, but does not seem to affect brain pathology (Zhao et al. 2012). As the protein ns4 of MHV-JHM has not been detected in infected cells, its function remains unknown. The ns5 protein also has unknown functions but may antagonize the interferon response (Koetzner et al. 2010).

\section{Life Cycle}

\section{Cell Entry}

Neurotropic members of the Coronaviridae family utilize both host cell proteins and host cell carbohydrates as receptors for binding and entry (reviewed in Masters 2006). MHV infection of host cells involves specific interaction of the $\mathrm{S}$ glycoprotein with a proteinaceous host cell receptor, carcinoembryonic antigen cell adhesion molecule (CEACAM-1a) (Williams et al. 1991); however, the pregnancy-specific glycoprotein (PSG) and other isoforms of CEACAM have also been shown to serve as a receptor for some strains of MHV. While PSG is expressed at high levels in the CNS (Chen et al. 1995), only CEACAM-1a has been definitely proven to be the receptor used in mice (Hemmila et al. 2004). The $\mathrm{S}$ protein consists of two functional domains: the $\mathrm{S} 1$ domain is responsible for host cell receptor binding and is prone to mutation, while the S2 domain mediates fusion with the host cell membrane and is more conserved between MHV strains. The receptor-binding domain of the MHV S protein is present within residues 1-330 of the protein (Kubo et al. 1994; Suzuki and Taguchi 1996; Taguchi et al. $1995)$, but the precise location of the fusion domain within the $S$ protein remains controversial. In many strains of MHV, cleavage of S into S1 and S2 domains is mediated by a furin-like enzyme and occurs during virus egress (Frana et al. 1985). However, for some coronaviruses, including MHV-2 and SARS-CoV, virion $\mathrm{S}$ protein is not cleaved during virus egress, but is cleaved in low $\mathrm{pH}$ endosomes by cathepsin (Huang et al. 2006b). The ligation of CEACAM-1a induces conformational changes between the S1 and S2 domains, which ultimately triggers fusion of the viral and host cell membranes. Virus entry can occur through one of two mechanisms. The viral envelope can fuse at neutral $\mathrm{pH}$ with the plasma membrane of the host cell, resulting in the uncoating and release of the viral genomic RNA into the cytoplasm. Alternatively, virus can be taken up into endocytic vesicles where $S$ protein is cleaved, followed by fusion of the viral envelope and host vesicle membranes with subsequent release of the genomic RNA into the cytoplasm. The latter process occurs at acidic $\mathrm{pH}$ and is inhibited by lysosomotropic agents such as chloroquine (Kooi et al. 1991; Nash and Buchmeier 1997). The replication life cycle of $\mathrm{MHV}$, like all coronaviruses, is believed to take place entirely within the host cell cytoplasm (reviewed in Masters 2006).

For HCoV-OC43, cellular binding and entry involves ligation of the $\mathrm{S}$ protein to sialidated carbohydrate moieties on the surface of cells (Vlasak et al. 1988b), while for SARS-CoV, entry requires binding to the angiotensin-converting enzyme (ACE2) (Li 
et al. 2003). As with MHV, entry of SARS-CoV, MERS, or HCoV-OC43 involves conformational changes in the $S$ protein, cleavage by one of several identified proteases and functional activation of the fusogenic S2 domain. Fusion of SARS-CoV and MERS has been more characterized than fusion of MHV (reviewed in Millet and Whittaker 2014).

\section{Genome Replication}

Because the genomes of coronaviruses are 5' capped and polyadenylated RNA, replication begins immediately after virus entry via direct translation of the genome by host cell machinery (Fig. 2). The translation of the viral RNA genome results in the generation of

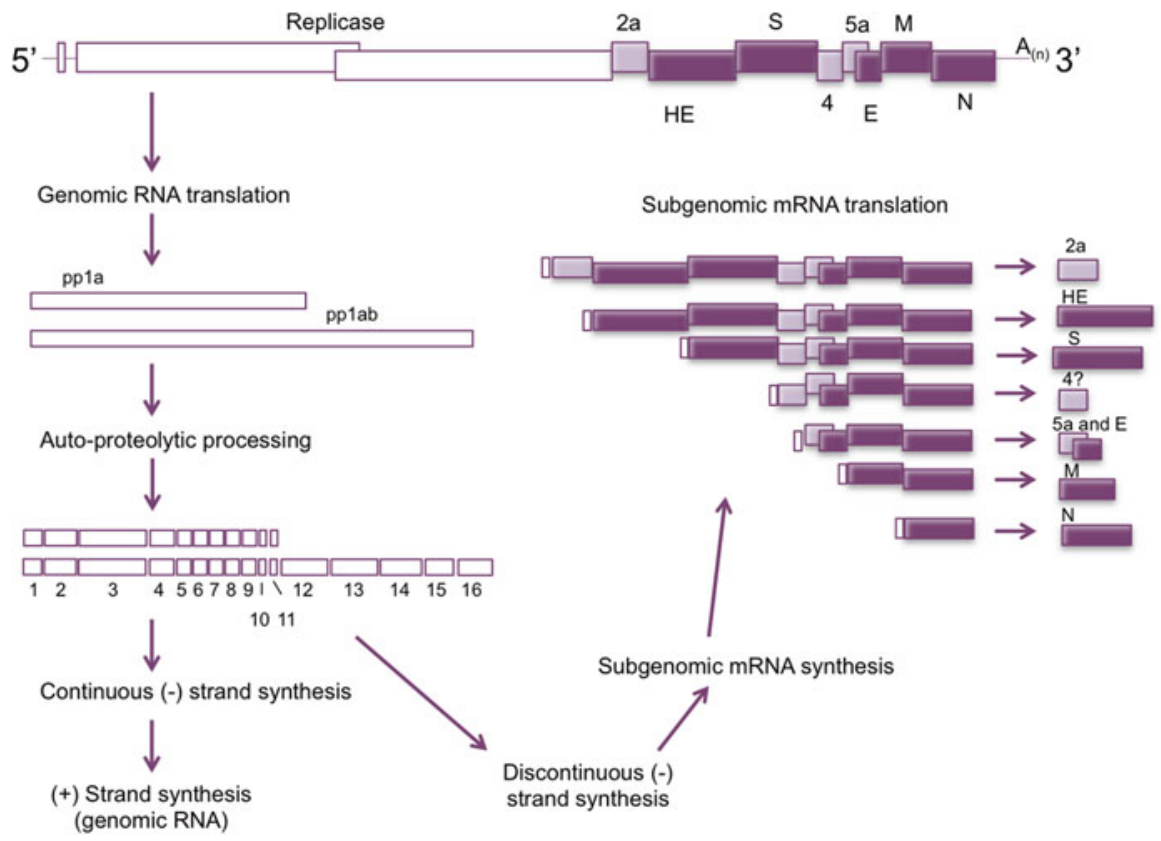

Fig. 2 Overview of coronavirus replication. Upon uncoating, virus RNA is directly translated via host cell machinery into two large polyproteins, pp1a and pp1ab. Both polyproteins undergo autoproteolytic processing to generate nonstructural proteins (nsp) of the replicase gene complex (nsp1-nsp16). The replicase proteins mediate continuous or discontinuous replication of negativestrand RNA templates. Genome-length negative strands serve as template for the replication of the genomic, positive-strand RNA that is packaged into virions. Discontinuous replication results in subgenomic-length negative strands that serve as template for the nested set of subgenomic messenger RNAs (mRNA). mRNA is translated by host cell machinery into structural and accessory proteins. E, M, and S proteins assemble on intracellular membranes, along with newly synthesized full-length, positive-strand RNA that has been encapsidated by the N protein. Virus assembly occurs in the endoplasmic reticulum Golgi intermediate complex (ERGIC), and eventual release of virus particles occurs through host cell secretory pathways 
two large polyproteins, pp1a (450-500 kDa) and pp1ab (750-800 kDa): the translation of the second is a result of a $(-1)$ ribosomal frame shift at a pseudoknot structure during translation of ORF1a (Brierley et al. 1989). The polyprotein is processed into component proteins by at least two different viral proteases, a papain-like proteinase and a second proteinase with some properties similar to those of the picornavirus $3 \mathrm{C}$ protease $\left(\mathrm{M}^{\text {pro }}\right)$. In addition to a viral $\mathrm{RdRp}$ and helicase, coronaviruses encode several novel proteins including a uridylate-specific endoribonuclease (NendoU), a $3^{\prime}$ to $5^{\prime}$ exoribonuclease (ExoN), and a $2^{\prime}$ - $O$-ribose methyltransferase, which are likely critical for viral RNA synthesis. The $3 \mathrm{C}$ - and papain-like proteinases auto-process the large polyproteins either during or after translation (Ziebuhr et al. 2000). Sixteen total proteins are generated from the two large polyproteins (nsp1-16), eight of which are predicted to have enzymatic activity (reviewed in Weiss and Leibowitz 2011) Interestingly, while many of the described functions of nsp1-16 are common to RNA viruses and are clearly important for virus replication or transcription, several others are wholly unique to coronaviruses and may play important roles in modulating cellular processes (Snijder et al. 2003). For example, the viral $2{ }^{\prime}-O$-ribose methyltransferase is important in immune evasion (Daffis et al. 2010).

The replication of viral RNA is critically dependent on key cis-acting sequence elements present at both the $5^{\prime}$ and $3^{\prime}$ ends of the genome, and within the genome (Lai and Cavanagh 1997; Masters 2006; Sawicki et al. 2007) (see below). The viral RdRp initiates negative-strand synthesis via recognition of signals at the $3^{\prime}$ end of the RNA genome. Interestingly, this process can be continuous, resulting in genomelength negative-strand molecules, or discontinuous, resulting in the generation of a nested set of subgenomic negative-strand templates (transcription, Fig. 2). Genomelength negative strands serve as template for RdRp-mediated synthesis of positivestrand, genome-length RNA that eventually is packaged into new virions.

\section{Transcription}

In addition to the elements required for replication, cis-acting elements within the genomic sequence termed transcription-regulating sequences (TRS), are required for transcription. TRS elements are located in the $5^{\prime}$ leader sequence and in front of each ORF (Fig. 1b). As described above, negative-strand synthesis can be discontinuous, resulting in subgenomic-length RNA molecules. It is generally believed that subgenomic RNA is produced during negative RNA synthesis (Sawicki et al. 2007). During negative-strand synthesis, elongation by viral RdRp proceeds from the $3^{\prime}$ end of the positive-strand genome until the first functional TRS sequence. At this point, via mechanisms that are unclear, the RdRp either continues to elongate (to generate genome-length negative-strand RNA) or dissociates from the positive strand, relocates to the $5^{\prime}$ end of the positive strand, and reinitiates elongation of the nascent negative strand with subsequent incorporation of the $5^{\prime}$ antileader sequence. The newly synthesized negative-strand RNA, with 5' leader incorporated, then serves as template for subgenomic-length mRNA synthesis. The subgenomic mRNAs are subsequently translated via host cell machinery into structural and nonstructural proteins. 


\section{Virus Assembly and Egress}

After translation by host cell machinery, key structural proteins including $\mathrm{E}$ and $\mathrm{M}$ traffic to and assemble on intracellular membranes located in the endoplasmic reticulum and Golgi regions (Vennema et al. 1996). The S protein also co-localizes at these sites of $\mathrm{E}$ and $\mathrm{M}$ accumulation and has a more disperse distribution throughout the cell. Full-length genomic RNA is encapsidated by the $\mathrm{N}$ protein via specific binding between $\mathrm{N}$ or $\mathrm{M}$ and a packaging signal present on viral genomic, but not subgenomic RNA, located in gene 1 (Molenkamp and Spaan 1997; Narayanan et al. 2003). Deletion of this packaging signal results in subgenomic RNA incorporation into the virion, and loss of selective advantage for the virus (Kuo and Masters 2013). Virus assembly, thought to be driven by both hostand virus-specific factors, occurs in the ERGIC, but the details are not fully understood. Virus egress occurs when the particles are released from the cell, probably at least in part, through host cell secretory processes similar to exopinocytosis.

\section{Transmission and Epidemiology}

\section{Intraspecies Transmission}

Mechanisms of transmission vary among the coronaviruses. For naturally occurring enteric strains of MHV, virus is transmitted via the fecal-oral route (Compton et al. 1993). Enteric strains of MHV are highly contagious and, once introduced into a mouse colony, virus spreads rapidly, eventually infecting all mice. Eradication of the virus from a colony is essentially impossible, and generally requires the destruction of the colony. Neurotropic strains of MHV, such as MHV-JHM, do not spread to uninfected animals, even those within the same cage, even though these strains are highly virulent. For respiratory coronaviruses, including $\mathrm{HCoV-OC43,} \mathrm{HCoV-229E,} \mathrm{MERS-CoV,} \mathrm{and} \mathrm{SARS-}$ $\mathrm{CoV}$, virus is spread via large droplets and contact. Additionally, SARs-CoV is detected in the feces and may have spread via the fecal-oral route during the 2002-2003 epidemic (Peiris et al. 2003b). The relative transmissibility of human respiratory/enteric coronaviruses is not precisely known, but epidemiologic studies of the SARS outbreak of $2002 / 2003$ suggest that aerosol transmission of SARS-CoV is not very efficient, but is most important during superspreading events and when patients are undergoing aerosolgenerating procedures. SARS-CoV was almost always transmitted from patients after they developed clinical signs (Lipsitch et al. 2003; Peiris et al. 2004).

\section{Interspecies Transmission}

Like all RNA viruses, the coronavirus RNA-dependent RNA polymerases lack proofreading activity; therefore, these viruses exist as a quasi-species, with several variants present in the population at any given time. For some coronaviruses, the 
result of this rapid ability to evolve is manifested by the ability to cross-species, with rapid adaptation to growth within the new host. This has been illustrated in in vitro studies, in which MHV was shown to readily adapt to the use of alternate receptors (Baric et al. 1997, 1999; Schickli et al. 1997, 2004; Thackray and Holmes 2004). In addition, SARS-CoV crossed species from Chinese horseshoe bats to infect animals such as the Himalayan palm civet and Chinese ferret badger, which in turn led to infection of humans (Guan et al. 2003; Lau et al. 2005; Li et al. 2005). Similarly, MERS-CoV is thought to have originated in bats (Wang et al. 2014) with camels as an intermediate host (Hemida et al. 2014). In fact, MERS-CoV can infect cells from a wide array of animal species (Barlan et al. 2014; Raj et al. 2013). Lastly, bovine coronavirus $(\mathrm{BCoV})$ and $\mathrm{HCoV}-\mathrm{OC} 43$ are very closely related and careful genetic analyses suggested that the virus crossed species about 100 years ago (Vijgen et al. 2005). Thus, at least for some coronaviruses, there is a substantial body of evidence that suggests interspecies transmission can occur, both in the laboratory and in natural infections.

\section{Pathogenesis of MHV-Induced Disease}

While several coronaviruses infect and replicate in the CNS, the pathogenesis and host response in mice infected with neurovirulent strains of MHV have been most intensively studied. Thus, this section of the chapter will focus on results from classic studies and recent advances that have contributed to our understanding of coronavirus pathogenesis in the CNS. The central theme of MHV-induced pathology is that the host immune response contributes in large part to host morbidity and mortality.

The neurovirulence and severity of MHV-induced CNS disease, as well as the nature of the host immune response, is dependent on the strain of MHV, the route of inoculation, and the age and genetic strain of the murine host. Two well-characterized laboratory strains of MHV are the John Howard Mueller (JHM) and the A59 strains. MHV strain JHM (MHV-JHM) was originally isolated from a single mouse with hind limb paralysis (Bailey et al. 1949; Cheever et al. 1949). Serial passage through suckling mouse brains resulted in the selection of viruses that caused rapid and fatal encephalitis in adult mice (Weiner 1973; Weiner et al. 1973). However, this pool also contained less virulent viruses, that were isolated as described below. MHV strain A59 is a naturally occurring variant of MHV that was isolated from a mouse with severe hepatitis (Manaker et al. 1961). MHV-JHM and A59 are very distinct from one another in their relative infectivity, spread, cell tropism, and neurovirulence. While A59 is generally hepatotropic, intracranial, or intranasal inoculation of mice with an appropriate amount of virus can result in a persistent infection of the CNS characterized by chronic demyelination and minimal parenchymal inflammation (Lavi et al. 1984b, 1986). On the other hand, intracranial or intranasal inoculation of mice with the most neurovirulent strains of MHV-JHM generally results in rapid and fatal encephalitis. Attenuated variants of MHV-JHM have been selected from these initial pools by limiting dilution assays (with identification by plaque 
size), by chemical mutagenesis, by exposure to neutralizing antibodies and by cold sensitivity. These attenuated variants are commonly used to study mechanisms of virus persistence and virus- and immune-mediated demyelination. Treatment of viral stocks with the anti-S protein neutralizing monoclonal antibody, J2.2, resulted in one of the most commonly studied attenuated variants, termed 2.2-V-1 (alternatively, rJ2.2) (Fleming et al. 1986). Unlike the parental strain of MHV-JHM, 2.2$\mathrm{V}-1$ preferentially infects oligodendrocytes and minimally infects neurons. Because this variant is relatively neuroattenuated, infected mice uniformly survive the acute infection but remain persistently infected. The disease course and the nature of the host immune response make infection with 2.2-V-1 particularly useful for examining the host response to persistent virus infection of the CNS, and for studying virus-induced immune-mediated pathology.

Initial studies with MHV-JHM suggested that demyelination was largely virusmediated (Lampert et al. 1973; Weiner 1973). However, subsequent studies showed that irradiated mice or congenitally immunodeficient mice (mice with severe combined immunodeficiency [SCID] or deficient in recombination activation gene activity $\left[\mathrm{RAG}^{-/}\right]$) do not develop demyelination (Houtman and Fleming 1996a; Wang et al. 1990; Wu and Perlman 1999). Moreover, during the course of viral infection, demyelination occurs in immunocompetent mice and in SCID or RAG ${ }^{-/-}$ mice reconstituted with immune cells. Thus, the host immune-effector cells that enter the CNS to protect from the acute phase of the infection can ultimately cause immunopathology during the persistent phase, leading to tissue damage and clinical evidence of demyelinating disease. Because infection with MHV can result in persistent infection with subsequent demyelinating disease, MHV is widely used as a model of the human disease multiple sclerosis (MS).

\section{CNS Cell Tropism and Virus Spread}

Interestingly, not all cells that express CEACAM-1a support productive infection and replication of MHV, and cells that support replication may have very low levels of receptor on their surface. The best example of the former phenomenon is the inability of MHV to productively infect B-cells, despite very high surface expression levels of CEACAM-1a (Morales et al. 2001). In addition, MHV replicates efficiently in the CNS of mice despite extremely low levels of CEACAM-1a mRNA and protein expression in this tissue (Godfraind et al. 1995, 1997; Nakagaki et al. 2005). These observations suggest that virus or host cellular factors other than CEACAM-1a also contribute to productive infection, and other data indicates that MHV can spread in CNS-derived cells independent of CEACAM-1a expression (Gallagher et al. 1992; Nash and Buchmeier 1996). This phenomenon occurs only with highly fusogenic strains of MHV-JHM and only when the S protein is expressed on the surface of cells. It is postulated that $\mathrm{S} 1$ is released from the $\mathrm{S}$ protein when expressed on the surface, exposing the fusogenic S2 fragment. If an uninfected cell is in close proximity, virus may spread, even in the absence of specific 
receptor. In fact, virus spreads in a receptor-independent manner in the CNS of CEACAM1 $\mathrm{a}^{-/-}$knockout mice (Miura et al. 2008).

Resident CNS cell types that support MHV-A59 and MHV-JHM replication include neurons, microglia, astrocytes, and oligodendrocytes. Importantly, the relatively more neurovirulent strains, such as MHV-JHM, exhibit an enhanced ability to infect and replicate in neurons (Fleming et al. 1986). As discussed below, the infection of neurons and astrocytes may directly contribute to virus persistence in the CNS, as these cell types do not express similar levels of major histocompatibility complex (MHC) class I or class II antigen as compared to other tissues (Aloisi et al. 2000; Fabry et al. 1994; Hickey 2001).

Spread of the virus within the CNS has been studied extensively. In models of intracranial inoculation, virus appears to first infect ependymal cells in the brain and spinal cord (Wang et al. 1992b). Here the virus replicates rapidly and then migrates into the brain and spinal cord parenchyma. In the parenchyma, several cell types support replication of MHV, including astrocytes, macrophages, microglia, and oligodendrocytes. In contrast to intracranial inoculation, after intranasal inoculation, MHV first infects and replicates in the olfactory nerve and bulb, and then spreads transneuronally to infect distal parts of the brain that are linked through neuroanatomic connections of the main olfactory bulb (MOB) (Barnett et al. 1993; Lavi et al. 1988). The virus disseminates via retrograde spread along axonal tracts to the spinal cord (Barnett et al. 1993). Eventual spread of the virus to the white matter and infection of oligodendrocytes in the spinal cord likely involves infection of astrocytes, a cell type readily infected in vitro and in vivo (Sun and Perlman 1995). Astrocytes are intimately associated with neurons in the gray matter and with oligodendrocytes and neurons in the white matter. Demyelination occurs when the host immune response attempts to clear virus from this site of infection.

\section{Acute Encephalitis Mediated by MHV-JHM}

Infection with virulent MHV-JHM results in acute encephalitis, with extensive neuronal infection (Lampert et al. 1973; Weiner 1973). This disease is similar to acute encephalitis caused by several other virulent viruses and has not been extensively characterized. While the precise mechanisms by which MHV-JHM causes death in acutely infected hosts remain unclear, it is likely that rapid replication and broad cell-type tropism of the more virulent strains of MHV contribute to general neurologic dysfunction. Widespread apoptosis in CNS-resident cells is not generally observed after acute MHV-JHM-induced encephalitis (Phillips et al. 2002; Wu and Perlman 1999). However, the extent to which direct virus destruction of infected cells contributes to the death of the mouse is unknown, and recent data suggest that this disease, like the chronic demyelinating disease, may also be partly immune-mediated. 


\section{Persistent CNS Infection by MHV-JHM}

Infection of the CNS by virulent MHV-JHM results in rapidly lethal encephalitis in the majority of mice. However, in mice protected by antivirus antibody or T-cells, or in mice infected with the less virulent variant $2.2-\mathrm{V}-1$, a variable percentage of mice survive the acute phase of infection and exhibit chronic disease characterized by hind limb paralysis and demyelination of the spinal cord (Fleming et al. 1986). The virus replicates at high titers during the acute phase with replication peaking at approximately 5 days post-infection (p.i.). In mice that survive the acute disease, the virus cannot be recovered from mice beyond approximately 2 weeks p.i., but virus antigen and RNA can be identified in the CNS out to 1 year post infection (Adami et al. 1995; de Aquino et al. 2014; Lavi et al. 1984a; Rowe et al. 1997; Zhao et al. 2009). As virus replication increases in the CNS, the integrity of the blood-brain barrier (BBB) is disturbed such that host inflammatory cells are now able to enter the CNS (Zhou et al. 2003). Interestingly, the infiltration of inflammatory cells coincides with the onset of clinical disease. Chronic inflammatory changes in the spinal cord of mice likely result in ongoing clinical disease and the progression of demyelination.

Several factors likely contribute to the ability of MHV to persist in the CNS of experimentally infected mice. First, several target cells of MHV infection in the mouse CNS (e.g., astrocytes, oligodendroglia, and neurons) do not express high levels of MHC class I or MHC class II antigen in the absence of injury (Aloisi et al. 2000; Fabry et al. 1994; Hickey 2001; Malone et al. 2008). Thus, by virtue of the cellular tropism of the virus, persistently infected cells may not serve as targets for virus-specific cytotoxic CD8 T-cells (CTL) that enter the CNS. On the other hand, virus-specific CD8 T-cells do become activated and traffic to the CNS of infected mice, and the ability of CTL to recognize and eliminate infected target cells is inferred from the analyses of $\mathrm{MHV}$-infected, antibody-protected suckling mice (model described below) (Perlman and Pewe 1998). Second, the brain is a tissue subject to minimal immune surveillance (Hickey 2001; Ransohoff and Engelhardt 2012; Ransohoff et al. 2003), so virus could replicate for longer periods of time and to higher titers while remaining undetected. Third, as both macrophages and microglia can be infected by MHV, and both are critical antigen-presenting cells in the CNS, direct infection of these cells might influence the overall presentation of virusspecific antigens in the CNS. In support of this possibility, MHV infects both macrophages and dendritic cells in vitro, and infection of these cells results in diminished ability to activate virus-specific CD8 T-cells (Turner et al. 2004; Zhou et al. 2003). Interestingly, CNS infection results in downregulation of CEACAM-1a receptor expression on macrophages and microglia (Ramakrishna et al. 2004). CEACAM-1a downregulation was specifically linked to the infiltration of CD4 T-cells. It is not known whether this phenomenon is strictly MHV-specific or whether this also occurs during infection of the CNS with other neurotropic viruses; however, it is postulated that this phenomenon may contribute to MHV persistence via retargeting of the virus to other cell types or by limiting T-cell activation in the CNS. Finally, prolonged infection of the CNS results in a loss of effector function by CD8 T-cells. MHV- 
JHM-specific CD8 T-cells isolated from the persistently infected CNS still express cytokines such as interferon-gamma (IFN- $\gamma$ ) on exposure to antigen directly ex vivo but no longer are able to lyse infected targets (Bergmann et al. 1999).

\section{Other Experimental Models of MHV Infection}

In addition to infecting mice, MHV is also capable of infecting and replicating in the CNS of rats (Barac-Latas et al. 1997; Nagashima et al. 1978; Sorensen et al. 1980; Watanabe et al. 1987), hamsters (Cheever et al. 1949) and nonhuman primates (Murray et al. 1992). While infection of monkeys can result in MHV-induced demyelinating disease, the mechanisms underlying this phenomenon have not been systematically examined. In contrast, much more is known about MHV-induced disease in rats. Infection generally results in fatal encephalitis in both suckling Lewis rats and suckling outbred animals; however, a percentage of rats do survive the acute disease. Infection of weanling rats results in variable disease, but infectious MHV can be recovered from all symptomatic animals. Disease in symptomatic animals is characterized by demyelination of the optic nerve, brainstem, and spinal cord, manifesting clinically as hind limb paralysis. In rats that remain asymptomatic, virus is neither recovered nor is there evidence of demyelination out to 60 days post-infection. In one study, the adoptive transfer of myelin-reactive T-cells from MHV-infected rats to naïve rats resulted in widespread CNS inflammation in the absence of demyelination (Watanabe et al. 1983). This is the only example suggesting that an autoimmune process contributes to demyelination in MHV-infected animals. Brown Norway rats are also susceptible to MHV infection, but these rats remain asymptomatic with evidence of subclinical levels of demyelination (Schwender et al. 1991) and little evidence for virus persistence or continued replication (Watanabe et al. 1987). The lack of clinical disease in Brown Norway rats is believed to be due to an effective antiviral neutralizing antibody response. The role of antiviral antibody responses in acute and chronic encephalitis is discussed in detail below.

\section{Role of MHV S Protein in Pathogenesis}

It is well established that the $\mathrm{S}$ protein of coronaviruses dictates species specificity and cell tropism. Additionally, a large body of evidence also suggests that the $\mathrm{S}$ protein influences pathogenesis and neurovirulence of MHV, presumably by altering cellular tropism (Fleming et al. 1986; Parker et al. 1989; Phillips et al. 2002) or efficiency of spread (Ontiveros et al. 2003; Phillips et al. 2002) within the CNS. Studies indicate that alterations in the S protein can also influence the nature and magnitude of the host innate and adaptive immune responses (MacNamara et al. 2005; Phillips et al. 2002; Rempel et al. 2004). The direct link between sequence changes in the $\mathrm{S}$ protein and altered neurovirulence stems from several 
analyses. Initial studies with viruses such as $2.2-\mathrm{V}-1$ showed that diminished disease severity correlated with mutation in the S glycoprotein (Fleming et al. 1986). A recombinant variant of MHV-A59 was engineered to express the MHV-JHM S glycoprotein (Navas and Weiss 2003; Phillips et al. 1999). This recombinant virus was nearly as virulent as parental MHV-JHM, manifested by increased infection of neurons, and did not exhibit the hepatotropism of MHV-A59.

\section{Innate Immune Response to MHV Infection}

Intracerebral or intranasal inoculation of mice with MHV-JHM results in a rapid and massive infiltration of host immune cells (reviewed in Bergmann et al. 2006). Soon after infection, infected and uninfected astrocytes elaborate chemokines and tissue remodeling factors that facilitate disruption of the blood-brain barrier (BBB) as well as recruit additional effectors of both the innate and adaptive arms of the host immune system (Lane et al. 2000; Trifilo et al. 2003; Zhou et al. 2002).

Important pro-inflammatory cytokines that are detected early in the infected CNS include IL-1 $\alpha$, IL-1 $\beta$, IL-6, and TNF (Rempel et al. 2004). Although IL-1 $\alpha$, IL-1 $\beta$, and IL-6 may directly and indirectly alter the permeability of the BBB and increase the expression of adhesion molecules on endothelial cells the role of TNF in modulating infection remains uncertain (Pewe et al. 2002; Stohlman et al. 1995). Depletion of TNF with neutralizing antibody does not change the inflammatory response, diminish virus clearance, or affect the demyelinating process (Stohlman et al. 1995). In addition, viral replication kinetics, expression of pro-inflammatory cytokines, and histopathological changes were similar in TNF-deficient mice and wild-type mice (Shirato et al. 2008).

The type I interferons, IFN-alpha and IFN-beta, are known to be critically important for establishing an antiviral state in virus-infected tissues. IFN- $\alpha / \beta$ has been shown to modestly inhibit MHV replication and infectivity in vitro (Pewe et al. 2002; Taguchi et al. 1985; Ye et al. 2007). However, several studies demonstrate that MHV infection does not trigger production of IFN- $\beta$ from the most infected cells (Garlinghouse et al. 1984; Pewe et al. 2005; Versteeg et al. 2007; Zhou and Perlman 2007). However, MHV-A59 induces IFN- $\alpha$ at high levels in plasmacytoid-dendritic cells after infection with MHV-A59 (Cervantes-Barragan et al. 2007) and MHVJHM induces IFN- $\beta$ by an MDA5-dependent pathway in macrophages and microglia in the brain of infected animals (Roth-Cross et al. 2008). Expression of type I interferon by plasmacytoid-dendritic cells (pDC) is likely important for innate control of coronavirus infection. In a recent study, mice genetically engineered to lack pDCs, had increased viral load and viral spread in MHV-A59 infected mice (Cervantes-Barragan et al. 2012). Ifit2, an IFN-stimulated gene, seems to be important as a regulator of IFN- $\alpha / \beta$ expression (Butchi et al. 2014). Of note, high levels of IFN- $\beta$ mRNA do not necessarily correlate with a favorable outcome. Mice infected with virulent MHV-JHM express high levels of IFN- $\beta$ in the CNS for prolonged periods of time, but express low levels of IFN- $\gamma$, and mount a minimal CD8 T-cell 
immune response. On the other hand, infection with MHV-A59 results in much lower levels of IFN- $\beta$ mRNA and an effective antiviral CD8 T-cell response (Iacono et al. 2006; Phillips et al. 2002; Rempel et al. 2004). These differences are also consistent with the notion that an effective adaptive immune response is critical for downregulating a prolonged and eventually deleterious innate immune response.

Important chemokines detected early in the CNS include MIP-2, CCL2, CCL3, CCL4, and CXCL10 (Lane et al. 1998; Rempel et al. 2004; Trifilo et al. 2004). Early release of the chemokines MIP-2, CCL2, CCL3, CCL4, and CXCL10 at the site of virus replication likely plays a critical role in recruiting inflammatory cells from the blood, as well as recruiting microglia and triggering the proliferation of astrocytes within the brain parenchyma. Levels of chemokines must be carefully balanced to effect optimal virus clearance and survival. In one study, constitutive transgenic expression of CCL2 in the CNS resulted in macrophage accumulation adjacent to the brain parenchyma. The presence of these partially primed cells might be expected to be protective upon subsequent infection with MHV. On the contrary, upon infection, CCL2 overexpression induced the accumulation of large numbers of alternatively activated macrophages, which were characterized by elevated YM-1 expression, and were immunosuppressive. The net result was decreased virus clearance and diminished survival (Trujillo et al. 2013).

CXCL10 is particularly important for recruiting T-cells to the MHV-infected CNS, and studies have shown that mice genetically deficient in CXCL10 have a much reduced T-cell response and worsened outcome after acute MHV infection (Liu et al. 2000, 2001). Moreover, infection of $\mathrm{RAG}^{1^{--}}$mice (which lack B- and T-cells) with a recombinant MHV engineered to express CXCL10 resulted in reduced virus titers, enhanced infiltration of NK cells, and protection from acute disease, suggesting that CXCL10 can also recruit natural killer (NK) cells, which may contribute to virus clearance in the absence of T-cells (Trifilo et al. 2004). In addition to the chemokines mentioned above, $\mathrm{ELR}^{+}$chemokines, CXCL1, CXCL2, and CXCL5 have a protective role within the acutely infected brain. Blocking with CXCR2 antibody (the receptor for ELR ${ }^{+}$cytokines), reduced the infiltration of neutrophils and virus-specific T-cells into the brain resulting in death from uncontrolled viral infection (Hosking et al. 2009). In addition to promoting protective antiviral responses in the CNS, the aforementioned cytokines and chemokines may also be pathogenic, as prolonged exposure of brain parenchyma cells to these factors could lead directly or indirectly to apoptosis or necrosis.

In response to deterioration of the BBB and upregulation of adhesion molecules on vascular endothelium, blood-derived inflammatory cells soon begin to infiltrate the infected CNS. By 3-5 days post-infection, there is a massive infiltration of macrophages, neutrophils, and NK cells (Bergmann et al. 1999; Zhou et al. 2003). Depletion of neutrophils with anti-Ly6C/G (Gr-1) antibody results in diminished BBB breakdown and enhanced virus replication (Zhou et al. 2003). These results are not completely straightforward, because GR-1 also depletes macrophages and some lymphocytes. However, they do indicate that inflammatory cell infiltrates are critical for BBB breakdown and inflammatory cell infiltration. Furthermore, macrophage depletion with liposome-encapsulated clodronate 
results in enhanced lethality, demonstrating an important role for macrophages in the initial response to infection (Xue et al. 1999). In addition to playing a critical role in protection from acute disease, macrophages also serve as critical effectors of the demyelinating process during chronic disease (Fig. 3). NK cells are detected at early times after infection as part of the initial response (Bukowski et al. 1983; Williamson and Stohlman 1990). While NK cells are known to secrete significant amounts of IFN- $\gamma$ in response to virus infection (Biron and Brossay 2001), there is little evidence that their presence is important in the host response to MHV in immunocompetent mice (Bergmann et al. 1999; Daniels et al. 2001; Marten et al. 2000b; Williamson et al. 1991). The possible exception to this may be the protective role of NK cells described above.

The initial MHV-induced inflammatory response in the CNS also includes the expression and secretion of tissue remodeling factors such as matrix metalloproteinases (MMP). Both inflammatory cells, such as neutrophils, and CNS-resident cells secrete MMPs. MMPs are thought to play a role in disrupting the $\mathrm{BBB}$, recruiting inflammatory cells, and activating CNS-resident and blood-borne cells for secretion of cytokines (Goetzl et al. 1996; Yong et al. 2001). Interestingly, only two MMPs have been shown to be consistently upregulated in response to MHV infection; MMP3, expressed primarily by astrocytes, and MMP12, expressed in large part by oligodendrocytes (Zhou et al. 2002, 2005). This is similar to the array of MMPs that are expressed during autoimmune and autoinflammatory processes such as experimental autoimmune encephalomyelitis (EAE) (Yong et al. 2001). Among the bloodborne inflammatory cells, neutrophils are known to secrete high levels of MMP9 upon entry and activation within the MHV-infected CNS. The complexity of the initial inflammatory response is underscored by the observation that a tissue-specific inhibitor of MMPs (TIMP-1) is also rapidly upregulated in the CNS in response to MHV infection (Zhou et al. 2005). TIMP-1 is known to negatively regulate the activation and function of MMPs. Thus, the upregulation and expression of TIMP-1 may serve to protect the CNS from overexuberant inflammation. Future studies are required to precisely define the roles of these pro- and anti-inflammatory mediators in the MHV-infected CNS.

\section{Innate Immune Factors That Influence Demyelination}

Key insight into the host-specific factors that mediate demyelination during acute and chronic infection comes from studies of mice that are genetically manipulated to abrogate some aspect of immune function or in which a key cell or cytokine/chemokine is depleted with neutralizing antibody. These systems have included the use of lethally irradiated mice and SCID or RAG1-deficient mice. Inoculation of any of these mice with 2.2-V-1 results in acute and chronic encephalitis in the absence of demyelination of the spinal cord (Houtman and Fleming 1996a; Wang et al. 1990; $\mathrm{Wu}$ and Perlman 1999). However, reconstitution of these mice with splenocytes results in the rapid development of demyelination. Demyelination is most 
reproducible when cells are transferred from MHV-JHM-immune mice. Transferred hyperimmune MHV-JHM-specific serum is able to mediate demyelination in MHVJHM-infected $\mathrm{RAG1}^{-/}$mice although not as robustly as virus-specific T-cells. Houtman and Fleming also showed that when mice lacking CD4 or CD8 T-cells were infected, demyelination developed, showing that neither cell type is required for this process (Houtman and Fleming 1996a). Subsequent work showed that several components of both the innate and adaptive immune system could mediate demyelination in the brains and spinal cords of these immunodeficient recipient mice. For example, in one study, Kim (Kim and Perlman 2005a) used targeted recombination to generate a virus recombinant version of $2.2-\mathrm{V}-1$ that expressed the macrophage chemoattractant MCP1/CCL2. Virus-derived CCL2, in the absence of any antiviral T-cells or antibody was sufficient to induce demyelination in the spinal cord. While demyelination via immune- or virus-mediated destruction of oligodendrocytes is considered to be primary (not secondary to axonal damage), T-cell-mediated damage of axons has been observed concomitant with demyelination. Although not proven, this process is probably cytokine-mediated (Dandekar et al. 2001). Of note, similar findings are observed in the CNS of MS patients and contribute to long-term, irreversible disability (Trapp et al. 1998). The cells and effector molecules that have been identified as playing a critical role in virus-induced demyelination are summarized in Fig. 3. Activated macrophages/microglia are a common feature of MHV-induced, immune-mediated demyelination as well as active lesions in patients with MS, suggesting that these cells may actually serve as the final effectors of this process. Macrophages enter the CNS as inflammatory monocytes and mature in situ. Maturation is characterized by the downregulation of Ly6C and the upregulation of CD11c, a molecule usually used to define dendritic cells. In this instance, it is not clear whether CD11c expression is involved in antigen presentation or if CD11c is only a maturation marker. In support of the latter, both CD11 $\mathrm{c}^{+}$and $\mathrm{CD} 11 \mathrm{c}^{-}$cells were found in proximity to areas of demyelination (Templeton et al. 2008).

As mentioned above, CXCL10 is another important chemokine in MHV-infected animals. In contrast to a protective role during acute infection, CXCL10 may play a pathogenic role during chronic MHV infection, as in vivo neutralization of CXCL10 in chronically infected mice resulted in both reduced demyelination and clinical signs of neurologic dysfunction (Liu et al. 2001). The ELR ${ }^{+}$chemokines are protective in both the acute and chronic phase. Through signaling of CXCR2, these cytokines protect oligodendrocytes from apoptosis and decrease demyelination as shown via CXCR2 neutralization (Hosking et al. 2010).

Collectively, these results suggest that a pro-inflammatory milieu is present in the MHV-infected RAG1 ${ }^{--}$or SCID CNS, but activated macrophages do not enter the spinal cord in the absence of an additional intervention (anti-MHV T-cells or antibody or overexpression of a macrophage chemoattractant). Once this trigger is provided, the process of demyelination is rapidly initiated, often accompanied by worsened clinical disease. Thus, macrophages serve as the final effectors of demyelination in MHV-infected mice. Demyelination occurs during the process of virus clearance, in areas devoid of virus antigen. A future research goal will be to determine how to maximize virus clearance without also causing myelin/oligodendrocyte destruction. 
a $\quad$ T and B cell mediated demyelination

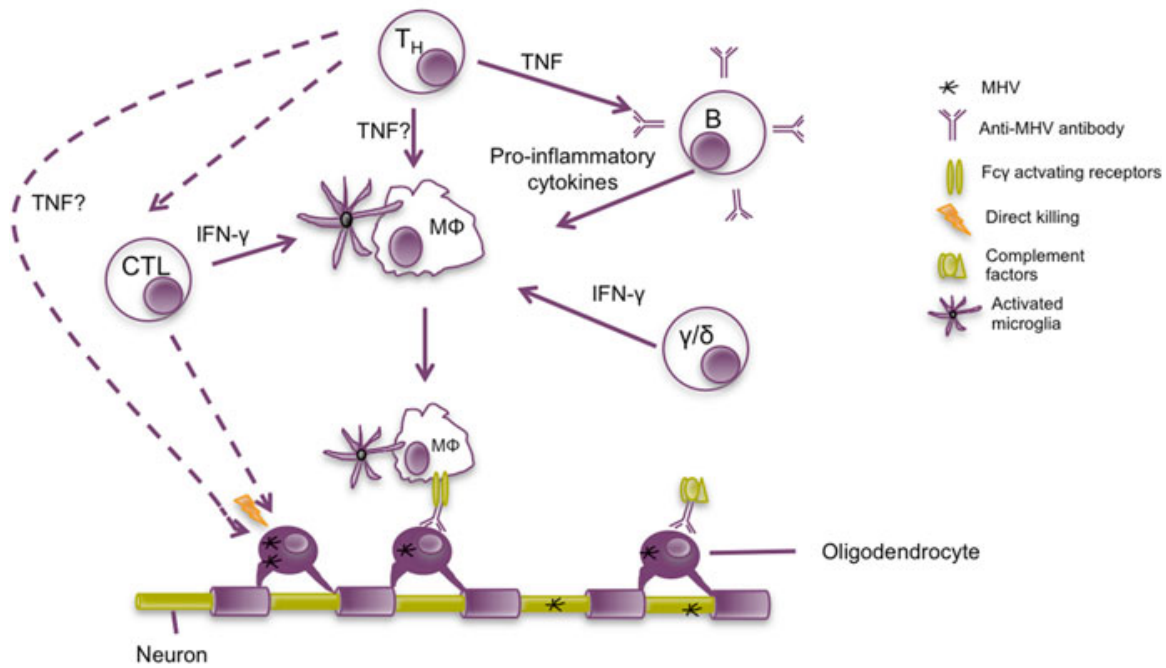

b T and B cell independent demyelination

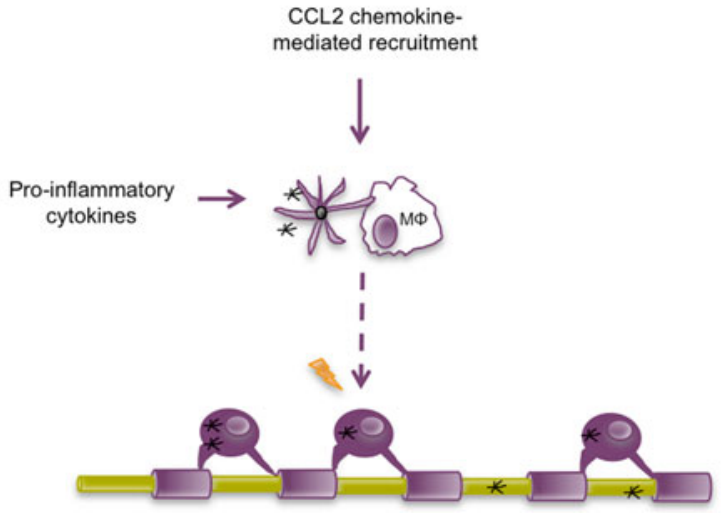

Fig. 3 Schematic representation of the host-specific factors and cell types that contribute to demyelination in the infected CNS. (a) Intranasal or intracranial MHV infection initiates an inflammatory cascade that results in the recruitment of CD8 $(\mathrm{CTL})$ and CD4 $\left(\mathrm{T}_{\mathrm{H}}\right) \mathrm{T}$-cells, B-cells, $\gamma / \delta$ T-cells, and macrophages $(M \Phi)$ to the CNS. CTL and $\mathrm{T}_{\mathrm{H}}$ cells may kill infected oligodendrocytes directly (dashed lines), but it more likely that they secrete pro-inflammatory cytokines that activate macrophages/microglia and damage oligodendrocytes (solid lines). $\mathrm{T}_{\mathrm{H}}$ cells also activate virus-specific B-cells, which in turn secrete antiviral antibody. Antivirus antibody and activated macrophages/ microglia are sufficient for destruction of oligodendrocytes and demyelination of spinal cords in MHV-infected mice; however, these processes are dependent on complement factors and Fc $\gamma$ activating receptors. (b) In the absence of T-and B-cells (SCID or RAG1 $1^{-/}$mice), virus-encoded chemokine-(e.g., MCP-1/CCL2) mediated recruitment and activation of macrophages is sufficient to trigger demyelination in one model. The common feature of macrophage/microglia activation in each scenario underscores the critical role of these two cell types in MHV-induced demyelination 


\section{Adaptive Immune Response to MHV Infection}

Despite the robust innate immune response described above, MHV-JHM continues to replicate and spread. Declines in virus replication are only observed after the appearance of antiviral T-cells in the CNS, which begins by day 5 p.i. and peaks at approximately day 7 and day 9 p.i. for CD8 and CD4 T-cells, respectively (Haring et al. 2001; Williamson and Stohlman 1990). CD8 T-cells exert antiviral activity via direct and indirect mechanisms, whereas CD4 T-cells are primarily responsible for augmenting the magnitude and quality of CD8 T-cell and B-cell responses (Phares et al. 2012a, b). Antiviral B-cells do not infiltrate the inflamed CNS until approximately 2-3 weeks p.i., but several lines of evidence suggest that this arm of the adaptive response is critical in suppressing virus replication and spread and preventing virus recrudescence during the persistent phase of disease (Matthews et al. 2001; Ramakrishna et al. 2002). As virus replication is controlled and infectious virus titers decrease, so does the number of innate and adaptive immune cells. However, virus-specific T- and B-cells are retained at low levels in the CNS of persistently infected mice (Marten et al. 2000b; Zhao et al. 2009).

Infiltrating T-cells are largely MHV-JHM-specific, but it is now clear that infection also results in the recruitment and activation of virus-nonspecific, bystander T-cells (Chen et al. 2005; Haring and Perlman 2003; Haring et al. 2002). Several lines of evidence suggest that efficient virus clearance is critically dependent on both CD8 and CD4 T-cells. Depletion of CD4 or CD8 T-cells prior to infection with MHV-JHM or infection of mice deficient in CD4 or CD8 T-cells results in incomplete virus clearance and increased morbidity and mortality (Houtman and Fleming 1996a; Williamson and Stohlman 1990). While clearly important for virus clearance, infiltrating CD8 and CD4 T-cells also appear to play a pathogenic role. CD4 and CD8 T-cells can be detected in the CNS of acutely encephalitic mice 1-2 days prior to the death of the animal, concomitant with the onset of virus clearance, consistent with, but not proving a role in both virus clearance and immunopathological disease.

\section{CD8 T-Cell Responses}

Several CD8 T-cell epitopes have been discovered in MHV. One dominant CD8 $\mathrm{T}$-cell epitope, located in a conserved region of the $\mathrm{N}$ protein, has been identified in $\mathrm{BALB} / \mathrm{c}$ mice. This epitope, $\mathrm{N} 318$, is $\mathrm{H}-2 \mathrm{~L}^{\mathrm{d}}$-restricted and encompasses residues N318-326 (Table 1). In C57BL/6 (B6) mice, at least two immunodominant CD8 T-cell epitopes are recognized. Approximately 30-50\% of CD8 T-cells that infiltrate the B6 CNS at the peak of the T-cell response specifically recognize the dominant epitope, S510 (H-2D $\mathrm{D}^{\mathrm{b}}$-restricted, S510-518) when measured by staining with MHC class I tetramer. A second population of infiltrating CD8 T-cells is specific for a subdominant epitope S598 (598-605; H-2K ${ }^{\mathrm{b}}$-restricted). Both epitopes are derived from the hypervariable region of the $\mathrm{S}$ protein. This region tolerates both deletions 
Table 1 CD8 T-cell epitopess of MHV recognized in MHV-infected mice

\begin{tabular}{l|l|l}
\hline $\begin{array}{l}\text { Mouse } \\
\text { strain }\end{array}$ & $\begin{array}{l}\text { MHV } \\
\text { protein }\end{array}$ & Amino acids \\
\hline C57BL/6 & S & $510-518$ \\
\hline C57BL/6 & S & $598-605$ \\
\hline BALB/c & $\mathrm{N}$ & $318-326$ \\
\hline
\end{tabular}

and mutations, although deleted virus is usually attenuated (Dalziel et al. 1986; Fleming et al. 1987; Lavi et al. 1990; Parker et al. 1989; Wang et al. 1992a).

CD8 T-cells mediate virus clearance from astrocytes and microglia/macrophages largely by perforin-mediated cytolysis, whereas clearance of virus from oligodendrocytes is primarily dependent upon IFN- $\gamma$ expression (Lin et al. 1997; Parra et al. 1999). CD8 T-cells are also capable of eliminating virus-infected cells via the FasL/ Fas pathway, but this mode of clearance does not play a prominent role in clearance of MHV in vivo (Parra et al. 2000). While direct cytolytic activity is a hallmark of CD8 T-cell effector function, this activity must be carefully controlled in the CNS to avoid destruction of neurons, which are not generally replaceable. As described above, cytolytic activity is rapidly turned off in the infected CNS, possibly facilitating virus persistence (Bergmann et al. 1999; Marten et al. 2000a, b).

The critical role for anti-MHV CD8 T-cells in virus clearance is illustrated by results obtained from analyses of infected suckling mice. As described above, infection of naïve mice with highly neurovirulent MHV-JHM is rapidly fatal. However, administration of antivirus antibody protects mice from MHV-JHM but virus persists (Buchmeier et al. 1984). In the suckling mouse experimental system, suckling mice are infected at 10 days post-natal and are nursed by dams that were previously immunized with MHV-JHM (Perlman et al. 1987). Maternal antibodies protect the mice from acute encephalitis and death; however, a variable percentage of survivors develop clinical signs of chronic disease (hind limb paralysis) by 3-8 weeks p.i. In each symptomatic mouse, virus recovered from the brain and spinal cord is mutated in the immunodominant S510 CD8 T-cell epitope (CTL escape variant virus). Thus, immune pressure exerted by a vigorous CD8 T-cell response on MHV-JHMinfected cells results in the selection of variant viruses that have undergone mutation in the immunodominant CD8 T-cell epitope (Pewe et al. 1996). Generally, a single mutant is isolated from each animal, with mutation detected in position 2-7 of the CD8 T-cell epitope that abrogates either binding to the MHC class I molecule or T-cell receptor binding. The biological relevance of CTL escape in MHV-JHM was demonstrated by showing that infection with the mutant viruses resulted in increased morbidity and mortality as compared to naïve mice infected with wild-type virus (Pewe et al. 1998). These results further underscore the notion that virus-specific CD8 T-cells are critical for controlling virus replication and that at least one CNSresident cell type required for virus maintenance or replication expresses MHC class I. That CTL escape variant viruses can be recovered from MHV-JHMinfected, antibody-protected mice is of particular importance, as CTL escape variants are generally only identified in humans infected with HIV or HCV or nonhuman 
primates infected with simian immunodeficiency virus (reviewed in Goulder and Watkins 2004). Therefore, this mode of establishing a persistent MHV-JHM infection has begun to provide key insight into the virus- and host-specific factors that influence the selection of CTL escape variant viruses, including the relative contribution of antiviral antibody (Dandekar et al. 2003), epitope immunodominance (Kim and Perlman 2003), and virus fitness and T-cell functional avidity (Butler et al. 2008a, b). For example, the anti-MHV antibody response at the site of infection is critical for preventing the development of CTL escape variants. CTL escape is rarely detected in BALB/b mice even though epitope S510 is recognized in this mouse strain, because, unlike B6 mice, a large number of virus-specific antibodysecreting plasma cells are detected in the infected CNS (Dandekar et al. 2003).

During the persistent infection, MHV-specific CD8 T-cells are retained in the CNS at low levels and can be detected out to greater than 70 days p.i. (Bergmann et al. 1999; Marten et al. 2000a, b; Zhao et al. 2009). These virus-specific T-cells are recruited from peripheral antigen-experienced and naive cells and retain the ability to degranulate and produce cytokines (Zhao et al. 2009). In addition to dramatically influencing the clearance of MHV early after infection, CD8 T-cells also play an important and varied role in mediating demyelination, as described below.

\section{CD4 T-Cell Responses}

Several MHV-derived CD4 T-cell epitopes are recognized in B6 and BALB/c mice (Table 2). B6 mice recognize at least three MHC class II-restricted epitopes derived from the MHV M protein (M133) or the S protein (S358, and S333) (Xue and Perlman 1997). M133 is immunodominant in B6 mice, with up to $25 \%$ of infiltrating CD4 T-cells exhibiting specificity for this epitope during the initial effector response (Haring et al. 2001; Zhao et al. 2009). Similarly, MHV-derived MHC class II-restricted epitopes have been identified in BALB/c mice in both the $\mathrm{S}$ protein (S333) and the $\mathrm{N}$ protein (N266), although neither elicits as strong a CD4 T-cell response as the M133 epitope (van der Veen 1996).

Virus-specific CD4 T-cells are important for MHV clearance. In the absence of CD4 T-cells, either by antibody-mediated depletion or through the use of mice genetically deficient in CD4 T-cells, there is a marked delay in clearance of MHV from the CNS (Houtman and Fleming 1996a; Pearce et al. 1994; Sutherland et al. 1997; Williamson and Stohlman 1990). Also, adoptive transfer of MHV-specific CD4 T-cell lines into infected mice or rats revealed that CD4 T-cells of multiple virus specificities could confer protection. While a reduction in clinical signs of acute encephalitis was uniformly observed, each virus-specific CD4 T-cell line exhibited variable effects on virus titers, demyelination, and CNS inflammation (Erlich et al. 1989; Korner et al. 1991; Stohlman et al. 1986, 1988; Yamaguchi et al. 1991). While not experimentally examined, these observations likely reflect differential production of cytokines, altered trafficking to the CNS, or altered expansion by each unique CD4 T-cell clone upon 
Table 2 CD4 T-cell epitopes of MHV recognized in MHV-infected mice

\begin{tabular}{l|l|l}
\hline $\begin{array}{l}\text { Mouse } \\
\text { strain }\end{array}$ & $\begin{array}{l}\text { MHV } \\
\text { protein }\end{array}$ & Amino acids \\
\hline C57BL/6 & M & $133-147$ \\
\hline C57BL/6 & S & $333-347$ \\
\hline C57BL/6 & S & $358-372$ \\
\hline BALB/c & $\mathrm{S}$ & $333-347$ \\
\hline BALB/c & $\mathrm{N}$ & $266-279$ \\
\hline
\end{tabular}

activation. In addition, several studies reveal that CD4 T-cells are important mediators of MHV-induced demyelination during persistent infection (described below).

The mechanisms by which CD4 T-cells contribute to virus clearance are not completely understood but likely involve release of pro-inflammatory cytokines, most importantly IFN- $\gamma$, which may promote antigen presentation by blood-borne and CNS-resident cells (Bergmann et al. 2006). Furthermore, depletion of CD4 T-cells correlated with decreased numbers of virus-specific CD8 T-cells infiltrating the brain parenchyma (Stohlman et al. 1998). Thus, secretion of cytokines that serve as survival or accumulation factors for CD8 T-cells may also be a key effector function of virus-specific CD4 T-cells that infiltrate the MHV-infected CNS. Although evidence for direct cytolytic activity of CD4 T-cells in vivo is lacking, one study (Heemskerk et al. 1995) demonstrated that virus-specific CD4 T-cells were able to lyse MHV-infected target cells in vitro. Moreover, the adoptive transfer of these cells to MHV-infected mice protected them from fatal encephalitis (Heemskerk et al. 1995; Wijburg et al. 1996). Further analyses on MHV-induced CNS disease in CD4-deficient mice revealed a role for CD4 T-cells in sustaining recruitment of macrophages and lymphocytes to the MHV-infected CNS. This lack of CD4 T-cells correlated with a decrease in the release of RANTES, a chemokine that has been shown to be critical for recruitment of leukocytes (Lane et al. 2000).

Similar to CD8 T-cells, evidence suggests that virus-specific CD4 T-cells also contribute to pathology associated with MHV infection of the CNS both during acute encephalitis and during persistent infection associated with demyelinating disease. A pathogenic role for CD4 T-cells during acute encephalitis was demonstrated by using targeted recombination to generate a lacking the immunodominant CD4 T-cell epitope, M133. Infection of mice with this recombinant resulted in $100 \%$ survival, in contrast to $100 \%$ mortality observed when mice were infected with wild-type virus (Anghelina et al. 2006). Introduction of a novel CD4 T-cell epitope into the variant virus reversed the phenotype, resulting in $50 \%$ mortality. The absence of this viral epitope had minimal effects on virulence in BALB/c mice, in which the M133 epitope is not recognized. Together, these results showed that the antivirus CD4 T-cell response and not some other factor caused more severe disease. The ratio of MHV-specific effector cells to T-regulatory cells may be critical for these different outcomes as transfer of Tregs decreased clinical disease and demyelination (Trandem et al. 2010). Interestingly, virus-specific Tregs exist and are even more suppressive compared to bulk Tregs, and inhibit pathogenic CD4 
T-cell responses (Zhao et al. 2014). These virus-specific Tregs function in both the draining lymph nodes and site of infection, the brain, to reduce the M133-specific CD4 T-cell response and to a lesser extent, the total anti-MHV CD4 T-cell response. Strikingly, these cells express IFN- $\gamma$ and TNF, cytokines usually associated with a pro-inflammatory immune response.

A substantial body of evidence suggests that CD4 T-cells also play a critical role in demyelination of the spinal cords of chronically infected mice and will be discussed below.

\section{T-Cell Responses Important for Demyelination}

As outlined above, MHV-JHM-induced demyelination is in large part immunemediated as $\mathrm{RAG}^{-/-}$and SCID mice do not develop demyelination in spite of high levels of virus replication in the CNS and the presence of elevated levels of several pro-inflammatory molecules such as TNF, MCP-1, CCL2, and IP-10/CXCL10 (Haring et al. 2001; Houtman and Fleming 1996b; Wang et al. 1990; Wu et al. 2000a, b; Wu and Perlman 1999). Initial experiments demonstrated that adoptive transfer of MHV-immune splenocytes to MHV-infected lethally irradiated mice results in both clinical and histological evidence of demyelination (Wang et al. 1990). Later, similar results were obtained after transfer of splenocytes into infected SCID or RAG1 ${ }^{-/-}$ mice: demyelination occurred with only modest reductions in virus titers (Dandekar et al. 2003; Pewe et al. 2002; Pewe and Perlman 2002; Wu et al. 2000a; Wu and Perlman 1999). Both primary effector cells (Wu and Perlman 1999) and memory T-cells (Bergmann et al. 2004) are able to mediate demyelination.

Subsequent analyses revealed that both MHV-JHM-experienced CD4 and CD8 T-cells can mediate demyelination after adoptive transfer into MHV-infected immunodeficient mice; however, the mechanisms by which these two cell types mediate demyelination is markedly different, as is the resulting clinical disease. Adoptive transfer of CD4 T-cell-enriched fractions resulted in severe clinical disease, with mice presenting as moribund by 7 days post-transfer (Pewe et al. 2002), sooner than is observed after transfer of undepleted splenocytes (Wu and Perlman 1999). In contrast, adoptive transfer of CD8 T-cell-enriched preparations resulted in widespread demyelination in the marked absence of severe clinical disease and only modest inflammation (Pewe and Perlman 2002). In addition, experiments using splenocytes isolated from mice deficient in IFN- $\gamma$, TNF, or perforin reveal several interesting features (Pewe et al. 2002; Pewe and Perlman 2002). Adoptive transfer of unfractionated splenocytes from IFN- $\gamma^{-/}$, perforin ${ }^{-/}$, or $\mathrm{TNF}^{-/}$mice resulted in similar amounts of demyelination as observed after transfer of wild-type cells. However, the transfer of CD8 T-cell-enriched fractions from IFN- $\gamma^{-/}$mice nearly completely abrogated demyelination (Pewe and Perlman 2002), similar to the effect observed in mice with CD8 $\mathrm{T}$ cell-mediated EAE (Huseby et al. 2001). The transfer of IFN- $\gamma^{-/-}$CD4 T-cellenriched fractions exacerbated demyelination and clinical disease (Pewe et al. 2002). This enhanced histological and clinical disease paralleled findings in mice with CD4 
T-cell-mediated EAE, in which more severe disease occurred in the absence of IFN- $\gamma$, reflecting an enhanced neutrophil infiltrate into the CNS (Tran et al. 2000). In contrast to IFN- $\gamma$, there were only modest reductions in demyelination after transfer of perforin $^{-/-}$or TNF ${ }^{-/-}$CD8 cells (Pewe and Perlman 2002). However, transfer of CD4 T-cells from $\mathrm{TNF}^{-/-}$resulted in milder disease with prolonged survival and only modest amounts of demyelination (S. Perlman, unpublished observations), suggesting that TNF produced by CD4 T-cells exacerbated clinical disease, the inflammatory response, and demyelination. These experiments illustrate the complexity of MHVinduced demyelination and show that the same effector molecule may have radically different effects, depending upon whether CD4 or CD8 T-cells express it.

In addition to conventional $\alpha / \beta$ T-cells, $\gamma / \delta$ T-cells are also able to mediate demyelination (Dandekar and Perlman 2002). In mice that lack a thymus (nude mice), conventional $\alpha / \beta$ T-cell development is compromised. However, a subset of T-cells expressing the $\gamma / \delta$ TCR develop athymically in these mice. Nude mice infected with $2.2-\mathrm{V}-1$ develop hind limb paresis/paralysis with histological evidence of demyelination of the spinal cord. In these animals, myelin destruction is mediated by $\gamma / \delta$ T-cells, since depletion of these cells abrogates myelin destruction. $\gamma / \delta$ T-cell-mediated demyelination, like that mediated by $\alpha / \beta$ CD8 T-cells, is dependent upon the expression of IFN- $\gamma$.

\section{Antibody Responses}

The critical role of antiviral antibody responses is best illustrated in 2.2-V-1-infected mice that lack either functional antibody ( $\mu$ chain (IgM)-deficient, $\mu$ MT mice) (Lin et al. 1999) or in mice that lack mature B-cells (Jh locus-deficient, JhD mice) (Ramakrishna et al. 2002). Initial virus clearance was not significantly impaired in these mice; however, several weeks p.i., virus recrudescence replicates to high titers, and eventually causes lethal encephalitis. Further experiments demonstrated a direct role for antibody in preventing re-emergence of virus, as passive administration of antivirus antibody to these mice prevented recrudescence until antivirus antibody was cleared. Of note, viruses that re-emerge in adult antibody-and B-cell-deficient mice exhibit no evidence of CTL escape, in contrast to MHV-infected antibody-protected suckling mice.

Analysis of MHV-infected Brown Norway rats also demonstrates a critical role of antivirus antibodies in protection from acute encephalitis. Brown Norway rats remain asymptomatic after challenge with virulent MHV-JHM. The presence of neutralizing antivirus antibody can be detected in the spinal fluid of these animals as early as 7 days p.i., which correlates with protection from acute encephalitis. While these antibodies protect Brown Norway rats from acute MHV-JHM-induced disease, subclinical demyelination can be detected as late as 2 months p.i. (Watanabe et al. 1987). The role of antibody in demyelinating disease is discussed below.

Recent evidence suggests that autoantibodies could potentially have a role in MHV-induced CNS pathology. While not detected in wild-type mice, transgenic mice engineered to express a CNS-specific autoantibody develop enhanced disease with more severe encephalitis upon infection with MHV (Burrer et al. 2007). 
Whether autoantibody production occurs to a significant extent in MHV-infected nontransgenic mice remains unknown.

\section{Anti-MHV Antibody Responses in Demyelination}

As discussed above, passive administration of antivirus antibody also results in demyelinating disease in 2.2-V-1-infected $\mathrm{RAG}^{-/-}$mice. Antibody-mediated demyelination is dependent upon both complement and $\mathrm{Fc} \gamma$-activating receptors since demyelination occurs to a much lesser extent in $\mathrm{FcR} \gamma^{-/}$mice and after depletion of complement with cobra venom factor (Kim and Perlman 2005b).

\section{Conclusions}

Due in part to the emergence of SARS in 2002 and MERS in 2012, and the continued potential for novel coronavirus emergence from zoonotic sources, new emphasis has been placed on understanding both coronavirus-induced pathology and the host immunological response to coronavirus infections. While much is known about the host-specific factors that contribute to demyelinating disease during persistent infection, there still is much to be learned about the pathogenesis of coronavirus infection. For example, the relative contribution of antigen presentation within the CNS by resident glial cells is largely unknown, and an understanding of the impact of coronavirus infection of the CNS on innate signaling events that eventually shape the adaptive immune response is incomplete. How macrophages cause demyelination and what T-cells or antibody do to assist macrophage recognition of damaged myelin and what cytokines may be involved are other questions to be answered. Virus spread within this CNS is also of interest. How does virus cross synapses and does this require receptor expression? Also of interest are the differential effects of infection on astrocytes, oligodendrocytes, and neurons.

Developing ways to combat virus replication during the acute phase of CNS infection while simultaneously minimizing damage to the CNS is an important and clinically relevant avenue of research. It is clear that the cells of the immune system that function to clear virus also contribute to morbidity of coronavirus-infected mice. One surprising observation has been that memory CD4 T-cells play an important role in modulating disease outcome during the acute infection. Thus, understanding the difference between effector and memory CD4 T-cells and the mechanisms of memory CD4 T-cell function in the acutely infected CNS will be of particular interest, as memory CD4 T-cells may also have broadly protective roles in encephalitides including human encephalitis.

In addition, continued work on how virus-specific factors contribute to acute and chronic encephalitis and on the curious predilection of coronaviruses to infect the CNS will enable development of therapeutic and prophylactic interventions. These 
strategies will likely provide novel strategies and new tools to modulate virus infection within the acutely infected CNS while minimizing damage to host tissue.

\section{References}

Adami C, Pooley J, Glomb J, Stecker E, Fazal F, Fleming JO, Baker SC (1995) Evolution of mouse hepatitis virus (MHV) during chronic infection: quasispecies nature of the persisting $\mathrm{MHV}$ RNA. Virology 209:337-346

Aloisi F, Ria F, Adorini L (2000) Regulation of T-cell responses by CNS antigen-presenting cells: different roles for microglia and astrocytes. Immunol Today 21:141-147

Anghelina D, Pewe L, Perlman S (2006) Pathogenic role for virus-specific CD4 T cells in mice with coronavirus-induced acute encephalitis. Am J Pathol 169:209-222

Bailey OT, Pappenheimer AM, Cheever FS, Daniels JB (1949) A murine virus (JHM) causing disseminated encephalomyelitis with extensive destruction of myelin: II. Pathology. J Exp Med 90:195-212

Barac-Latas V, Suchanek G, Breitschopf H, Stuehler A, Wege H, Lassmann H (1997) Patterns of oligodendrocyte pathology in coronavirus-induced subacute demyelinating encephalomyelitis in the Lewis rat. Glia 19:1-12

Baric RS, Sullivan E, Hensley L, Yount B, Chen W (1999) Persistent infection promotes crossspecies transmissibility of mouse hepatitis virus. J Virol 73:638-649

Baric RS, Yount B, Hensley L, Peel SA, Chen W (1997) Episodic evolution mediates interspecies transfer of a murine coronavirus. J Virol 71:1946-1955

Barlan A, Zhao J, Sarkar MK, Li K, McCray PB Jr, Perlman S, Gallagher T (2014) Receptor variation and susceptibility to Middle East respiratory syndrome coronavirus infection. J Virol 88:4953-4961

Barnett EM, Cassell MD, Perlman S (1993) Two neurotropic viruses, herpes simplex virus type 1 and mouse hepatitis virus, spread along different neural pathways from the main olfactory bulb. Neuroscience 57:1007-1025

Baudoux P, Carrat C, Besnardeau L, Charley B, Laude H (1998) Coronavirus pseudoparticles formed with recombinant $\mathrm{M}$ and $\mathrm{E}$ proteins induce alpha interferon synthesis by leukocytes. J Virol 72:8636-8643

Bergmann CC, Altman JD, Hinton D, Stohlman SA (1999) Inverted immunodominance and impaired cytolytic function of $\mathrm{CD} 8+\mathrm{T}$ cells during viral persistence in the central nervous system. J Immunol 163:3379-3387

Bergmann CC, Lane TE, Stohlman SA (2006) Coronavirus infection of the central nervous system: host-virus stand-off. Nat Rev Microbiol 4:121-132

Bergmann CC, Parra B, Hinton DR, Ramakrishna C, Dowdell KC, Stohlman SA (2004) Perforin and gamma interferon-mediated control of coronavirus central nervous system infection by CD8 T cells in the absence of CD4 T cells. J Virol 78:1739-1750

Biron CA, Brossay L (2001) NK cells and NKT cells in innate defense against viral infections. Curr Opin Immunol 13:458-464

Brierley I, Digard P, Inglis SC (1989) Characterization of an efficient coronavirus ribosomal frameshifting signal: requirement for an RNA pseudoknot. Cell 57:537-547

Buchmeier MJ, Lewicki HA, Talbot PJ, Knobler RL (1984) Murine hepatitis virus-4 (strain JHM)induced neurologic disease is modulated in vivo by monoclonal antibody. Virology $132: 261-270$

Bukowski JF, Woda BA, Habu S, Okumura K, Welsh RM (1983) Natural killer cell depletion enhances virus synthesis and virus-induced hepatitis in vivo. J Immunol 131:1531-1538

Burrer R, Buchmeier MJ, Wolfe T, Ting JP, Feuer R, Iglesias A, von Herrath MG (2007) Exacerbated pathology of viral encephalitis in mice with central nervous system-specific autoantibodies. Am J Pathol 170:557-566 
Butchi NB, Hinton DR, Stohlman SA, Kapil P, Fensterl V, Sen GC, Bergmann CC (2014) Ifit2 deficiency results in uncontrolled neurotropic coronavirus replication and enhanced encephalitis via impaired alpha/beta interferon induction in macrophages. J Virol 88:1051-1064

Butler NS, Theodossis A, Webb AI, Dunstone MA, Nastovska R, Ramarathinam SH, Rossjohn J, Purcell AW, Perlman S (2008a) Structural and biological basis of CTL escape in coronavirusinfected mice. J Immunol 180:3926-3937

Butler NS, Theodossis A, Webb AI, Nastovska R, Ramarathinam SH, Dunstone MA, Rossjohn J, Purcell AW, Perlman S (2008b) Prevention of cytotoxic T cell escape using a heteroclitic subdominant viral T cell determinant. PLoS Pathog 4:e1000186

Cervantes-Barragan L, Lewis KL, Firner S, Thiel V, Hugues S, Reith W, Ludewig B, Reizis B (2012) Plasmacytoid dendritic cells control T-cell response to chronic viral infection. Proc Natl Acad Sci U S A 109:3012-3017

Cervantes-Barragan L, Zust R, Weber F, Spiegel M, Lang KS, Akira S, Thiel V, Ludewig B (2007) Control of coronavirus infection through plasmacytoid dendritic-cell-derived type I interferon. Blood 109:1131-1137

Cheever FS, Daniels JB et al (1949) A murine virus (JHM) causing disseminated encephalomyelitis with extensive destruction of myelin. J Exp Med 90:181-210

Chen DS, Asanaka M, Yokomori K, Wang F, Hwang SB, Li HP, Lai MM (1995) A pregnancyspecific glycoprotein is expressed in the brain and serves as a receptor for mouse hepatitis virus. Proc Natl Acad Sci U S A 92:12095-12099

Chen G, Tai AK, Lin M, Chang F, Terhorst C, Huber BT (2005) Signaling lymphocyte activation molecule-associated protein is a negative regulator of the CD8 $\mathrm{T}$ cell response in mice. J Immunol 175:2212-2218

Compton SR, Barthold SW, Smith AL (1993) The cellular and molecular pathogenesis of coronaviruses. Lab Anim Sci 43:15-28

Daffis S, Szretter KJ, Schriewer J, Li J, Youn S, Errett J, Lin TY, Schneller S, Zust R, Dong H et al (2010) 2'-O methylation of the viral mRNA cap evades host restriction by IFIT family members. Nature 468:452-456

Dalziel RG, Lampert PW, Talbot PJ, Buchmeier MJ (1986) Site-specific alteration of murine hepatitis virus type 4 peplomer glycoprotein E2 results in reduced neurovirulence. J Virol 59:463-471

Dandekar AA, Jacobsen G, Waldschmidt TJ, Perlman S (2003) Antibody-mediated protection against cytotoxic T-cell escape in coronavirus-induced demyelination. J Virol 77:11867-11874

Dandekar AA, Perlman S (2002) Virus-induced demyelination in nude mice is mediated by gamma delta T cells. Am J Pathol 161:1255-1263

Dandekar AA, Wu GF, Pewe L, Perlman S (2001) Axonal damage is T cell mediated and occurs concomitantly with demyelination in mice infected with a neurotropic coronavirus. J Virol 75:6115-6120

Daniels KA, Devora G, Lai WC, O’Donnell CL, Bennett M, Welsh RM (2001) Murine cytomegalovirus is regulated by a discrete subset of natural killer cells reactive with monoclonal antibody to Ly49H. J Exp Med 194:29-44

de Aquino MT, Kapil P, Hinton DR, Phares TW, Puntambekar SS, Savarin C, Bergmann CC, Stohlman SA (2014) IL-27 limits central nervous system viral clearance by promoting IL-10 and enhances demyelination. J Immunol 193:285-294

de Groot RJ, Baker SC, Baric RS, Brown CS, Drosten C, Enjuanes L, Fouchier RA, Galiano M, Gorbalenya AE, Memish ZA et al (2013) Middle East respiratory syndrome coronavirus (MERS-CoV): announcement of the Coronavirus Study Group. J Virol 87:7790-7792

de Haan CA, Masters PS, Shen X, Weiss S, Rottier PJ (2002) The group-specific murine coronavirus genes are not essential, but their deletion, by reverse genetics, is attenuating in the natural host. Virology 296:177-189

Erlich SS, Matsushima GK, Stohlman SA (1989) Studies on the mechanism of protection from acute viral encephalomyelitis by delayed-type hypersensitivity inducer T cell clones. J Neurol Sci 90:203-216 
Fabry Z, Raine CS, Hart MN (1994) Nervous tissue as an immune compartment: the dialect of the immune response in the CNS. Immunol Today 15:218-224

Fleming JO, Trousdale MD, Bradbury J, Stohlman SA, Weiner LP (1987) Experimental demyelination induced by coronavirus JHM (MHV-4): molecular identification of a viral determinant of paralytic disease. Microb Pathog 3:9-20

Fleming JO, Trousdale MD, el-Zaatari FA, Stohlman SA, Weiner LP (1986) Pathogenicity of antigenic variants of murine coronavirus JHM selected with monoclonal antibodies. J Virol 58:869-875

Frana MF, Behnke JN, Sturman LS, Holmes KV (1985) Proteolytic cleavage of the E2 glycoprotein of murine coronavirus: host-dependent differences in proteolytic cleavage and cell fusion. J Virol 56:912-920

Gallagher TM, Buchmeier MJ, Perlman S (1992) Cell receptor-independent infection by a neurotropic murine coronavirus. Virology 191:517-522

Garlinghouse LE Jr, Smith AL, Holford T (1984) The biological relationship of mouse hepatitis virus (MHV) strains and interferon: in vitro induction and sensitivities. Arch Virol 82:19-29

Godeke GJ, de Haan CA, Rossen JW, Vennema H, Rottier PJ (2000) Assembly of spikes into coronavirus particles is mediated by the carboxy-terminal domain of the spike protein. J Virol $74: 1566-1571$

Godfraind C, Havaux N, Holmes KV, Coutelier JP (1997) Role of virus receptor-bearing endothelial cells of the blood-brain barrier in preventing the spread of mouse hepatitis virus-A59 into the central nervous system. J Neurovirol 3:428-434

Godfraind C, Langreth SG, Cardellichio CB, Knobler R, Coutelier JP, Dubois-Dalcq M, Holmes KV (1995) Tissue and cellular distribution of an adhesion molecule in the carcinoembryonic antigen family that serves as a receptor for mouse hepatitis virus. Lab Invest 73:615-627

Goetzl EJ, Banda MJ, Leppert D (1996) Matrix metalloproteinases in immunity. J Immunol 156:1-4

Goulder PJ, Watkins DI (2004) HIV and SIV CTL escape: implications for vaccine design. Nat Rev Immunol 4:630-640

Guan Y, Zheng BJ, He YQ, Liu XL, Zhuang ZX, Cheung CL, Luo SW, Li PH, Zhang LJ, Guan YJ et al (2003) Isolation and characterization of viruses related to the SARS coronavirus from animals in southern China. Science 302:276-278

Haring JS, Perlman S (2003) Bystander CD4 T cells do not mediate demyelination in mice infected with a neurotropic coronavirus. J Neuroimmunol 137:42-50

Haring JS, Pewe LL, Perlman S (2001) High-magnitude, virus-specific CD4 T-cell response in the central nervous system of coronavirus-infected mice. J Virol 75:3043-3047

Haring JS, Pewe LL, Perlman S (2002) Bystander CD8 T cell-mediated demyelination after viral infection of the central nervous system. J Immunol 169:1550-1555

Heemskerk MH, Schoemaker HM, Spaan WJ, Boog CJ (1995) Predominance of MHC class II-restricted CD4+ cytotoxic $\mathrm{T}$ cells against mouse hepatitis virus A59. Immunology 84:521-527

Hemida MG, Chu DK, Poon LL, Perera RA, Alhammadi MA, Ng HY, Siu LY, Guan Y, Alnaeem A, Peiris M (2014) MERS coronavirus in dromedary camel herd, Saudi Arabia. Emerg Infect Dis 20:1231-1234

Hemmila E, Turbide C, Olson M, Jothy S, Holmes KV, Beauchemin N (2004) Ceacam1a-/- mice are completely resistant to infection by murine coronavirus mouse hepatitis virus A59. J Virol 78:10156-10165

Hickey WF (2001) Basic principles of immunological surveillance of the normal central nervous system. Glia 36:118-124

Homberger FR, Barthold SW, Smith AL (1992) Duration and strain-specificity of immunity to enterotropic mouse hepatitis virus. Lab Anim Sci 42:347-351

Hosking MP, Liu L, Ransohoff RM, Lane TE (2009) A protective role for ELR+ chemokines during acute viral encephalomyelitis. PLoS Pathog 5:e1000648

Hosking MP, Tirotta E, Ransohoff RM, Lane TE (2010) CXCR2 signaling protects oligodendrocytes and restricts demyelination in a mouse model of viral-induced demyelination. PLoS One 5:e11340 
Houtman JJ, Fleming JO (1996a) Dissociation of demyelination and viral clearance in congenitally immunodeficient mice infected with murine coronavirus JHM. J Neurovirol 2:101-110

Houtman JJ, Fleming JO (1996b) Pathogenesis of mouse hepatitis virus-induced demyelination. J Neurovirol 2:361-376

Huang C, Narayanan K, Ito N, Peters CJ, Makino S (2006a) Severe acute respiratory syndrome coronavirus 3 a protein is released in membranous structures from 3a protein-expressing cells and infected cells. J Virol 80:210-217

Huang IC, Bosch BJ, Li F, Li W, Lee KH, Ghiran S, Vasilieva N, Dermody TS, Harrison SC, Dormitzer PR et al (2006b) SARS coronavirus, but not human coronavirus NL63, utilizes cathepsin L to infect ACE2-expressing cells. J Biol Chem 281:3198-3203

Hurst KR, Kuo L, Koetzner CA, Ye R, Hsue B, Masters PS (2005) A major determinant for membrane protein interaction localizes to the carboxy-terminal domain of the mouse coronavirus nucleocapsid protein. J Virol 79:13285-13297

Huseby ES, Liggitt D, Brabb T, Schnabel B, Ohlen C, Goverman J (2001) A pathogenic role for myelin-specific CD8(+) T cells in a model for multiple sclerosis. J Exp Med 194:669-676

Iacono KT, Kazi L, Weiss SR (2006) Both spike and background genes contribute to murine coronavirus neurovirulence. J Virol 80:6834-6843

Ito N, Mossel EC, Narayanan K, Popov VL, Huang C, Inoue T, Peters CJ, Makino S (2005) Severe acute respiratory syndrome coronavirus $3 \mathrm{a}$ protein is a viral structural protein. J Virol 79:3182-3186

Kazi L, Lissenberg A, Watson R, de Groot RJ, Weiss SR (2005) Expression of hemagglutinin esterase protein from recombinant mouse hepatitis virus enhances neurovirulence. J Virol 79:15064-15073

Kim TS, Perlman S (2003) Protection against CTL escape and clinical disease in a murine model of virus persistence. J Immunol 171:2006-2013

Kim TS, Perlman S (2005a) Viral expression of CCL2 is sufficient to induce demyelination in RAG1-/- mice infected with a neurotropic coronavirus. J Virol 79:7113-7120

Kim TS, Perlman S (2005b) Virus-specific antibody, in the absence of T cells, mediates demyelination in mice infected with a neurotropic coronavirus. Am J Pathol 166:801-809

Koetzner CA, Kuo L, Goebel SJ, Dean AB, Parker MM, Masters PS (2010) Accessory protein 5a is a major antagonist of the antiviral action of interferon against murine coronavirus. J Virol 84:8262-8274

Kooi C, Cervin M, Anderson R (1991) Differentiation of acid-pH-dependent and -nondependent entry pathways for mouse hepatitis virus. Virology 180:108-119

Korner H, Schliephake A, Winter J, Zimprich F, Lassmann H, Sedgwick J, Siddell S, Wege H (1991) Nucleocapsid or spike protein-specific CD4+ T lymphocytes protect against coronavirusinduced encephalomyelitis in the absence of CD8+ T cells. J Immunol 147:2317-2323

Ksiazek TG, Erdman D, Goldsmith CS, Zaki SR, Peret T, Emery S, Tong S, Urbani C, Comer JA, Lim W et al (2003) A novel coronavirus associated with severe acute respiratory syndrome. N Engl J Med 348:1953-1966

Kubo H, Yamada YK, Taguchi F (1994) Localization of neutralizing epitopes and the receptorbinding site within the amino-terminal 330 amino acids of the murine coronavirus spike protein. J Virol 68:5403-5410

Kuo L, Masters PS (2003) The small envelope protein E is not essential for murine coronavirus replication. J Virol 77:4597-4608

Kuo L, Masters PS (2013) Functional analysis of the murine coronavirus genomic RNA packaging signal. J Virol 87:5182-5192

Lai MM, Cavanagh D (1997) The molecular biology of coronaviruses. Adv Virus Res 48:1-100

Lampert PW, Sims JK, Kniazeff AJ (1973) Mechanism of demyelination in JHM virus encephalomyelitis. Electron microscopic studies. Acta Neuropathol 24:76-85

Lane TE, Asensio VC, Yu N, Paoletti AD, Campbell IL, Buchmeier MJ (1998) Dynamic regulation of alpha- and beta-chemokine expression in the central nervous system during mouse hepatitis virus-induced demyelinating disease. J Immunol 160:970-978 
Lane TE, Liu MT, Chen BP, Asensio VC, Samawi RM, Paoletti AD, Campbell IL, Kunkel SL, Fox HS, Buchmeier MJ (2000) A central role for CD4(+) T cells and RANTES in virus-induced central nervous system inflammation and demyelination. J Virol 74:1415-1424

Lau SK, Woo PC, Li KS, Huang Y, Tsoi HW, Wong BH, Wong SS, Leung SY, Chan KH, Yuen KY (2005) Severe acute respiratory syndrome coronavirus-like virus in Chinese horseshoe bats. Proc Natl Acad Sci U S A 102:14040-14045

Lavi E, Fishman PS, Highkin MK, Weiss SR (1988) Limbic encephalitis after inhalation of a murine coronavirus. Lab Invest 58:31-36

Lavi E, Gilden DH, Highkin MK, Weiss SR (1984a) Persistence of mouse hepatitis virus A59 RNA in a slow virus demyelinating infection in mice as detected by in situ hybridization. J Virol 51:563-566

Lavi E, Gilden DH, Highkin MK, Weiss SR (1986) The organ tropism of mouse hepatitis virus A59 in mice is dependent on dose and route of inoculation. Lab Anim Sci 36:130-135

Lavi E, Gilden DH, Wroblewska Z, Rorke LB, Weiss SR (1984b) Experimental demyelination produced by the A59 strain of mouse hepatitis virus. Neurology 34:597-603

Lavi E, Murray EM, Makino S, Stohlman SA, Lai MM, Weiss SR (1990) Determinants of coronavirus MHV pathogenesis are localized to $3^{\prime}$ portions of the genome as determined by ribonucleic acid-ribonucleic acid recombination. Lab Invest 62:570-578

Li W, Moore MJ, Vasilieva N, Sui J, Wong SK, Berne MA, Somasundaran M, Sullivan JL, Luzuriaga K, Greenough TC et al (2003) Angiotensin-converting enzyme 2 is a functional receptor for the SARS coronavirus. Nature 426:450-454

Li W, Shi Z, Yu M, Ren W, Smith C, Epstein JH, Wang H, Crameri G, Hu Z, Zhang H et al (2005) Bats are natural reservoirs of SARS-like coronaviruses. Science 310:676-679

Lin MT, Hinton DR, Marten NW, Bergmann CC, Stohlman SA (1999) Antibody prevents virus reactivation within the central nervous system. J Immunol 162:7358-7368

Lin MT, Stohlman SA, Hinton DR (1997) Mouse hepatitis virus is cleared from the central nervous systems of mice lacking perforin-mediated cytolysis. J Virol 71:383-391

Lipsitch M, Cohen T, Cooper B, Robins JM, Ma S, James L, Gopalakrishna G, Chew SK, Tan CC, Samore MH et al (2003) Transmission dynamics and control of severe acute respiratory syndrome. Science 300:1966-1970

Liu MT, Armstrong D, Hamilton TA, Lane TE (2001) Expression of Mig (monokine induced by interferon-gamma) is important in $\mathrm{T}$ lymphocyte recruitment and host defense following viral infection of the central nervous system. J Immunol 166:1790-1795

Liu MT, Chen BP, Oertel P, Buchmeier MJ, Armstrong D, Hamilton TA, Lane TE (2000) The T cell chemoattractant IFN-inducible protein 10 is essential in host defense against viral-induced neurologic disease. J Immunol 165:2327-2330

MacNamara KC, Chua MM, Phillips JJ, Weiss SR (2005) Contributions of the viral genetic background and a single amino acid substitution in an immunodominant CD8+ T-cell epitope to murine coronavirus neurovirulence. J Virol 79:9108-9118

Malone KE, Stohlman SA, Ramakrishna C, Macklin W, Bergmann CC (2008) Induction of class I antigen processing components in oligodendroglia and microglia during viral encephalomyelitis. Glia 56:426-435

Manaker RA, Piczak CV, Miller AA, Stanton MF (1961) A hepatitis virus complicating studies with mouse leukemia. J Natl Cancer Inst 27:29-51

Marten NW, Stohlman SA, Atkinson RD, Hinton DR, Fleming JO, Bergmann CC (2000a) Contributions of $\mathrm{CD} 8+\mathrm{T}$ cells and viral spread to demyelinating disease. J Immunol 164:4080-4088

Marten NW, Stohlman SA, Bergmann CC (2000b) Role of viral persistence in retaining CD8(+) T cells within the central nervous system. J Virol 74:7903-7910

Masters PS (2006) The molecular biology of coronaviruses. Adv Virus Res 66:193-292

Masters PS, Perlman S (2013) Coronaviridae. In: Knipe DM, Howley PM (eds) Fields virology. Lippincott Williams \& Wilkins, Philadelphia, pp 825-858

Matthews AE, Weiss SR, Shlomchik MJ, Hannum LG, Gombold JL, Paterson Y (2001) Antibody is required for clearance of infectious murine hepatitis virus A59 from the central nervous system, but not the liver. J Immunol 167:5254-5263 
Millet JK, Whittaker GR (2014) Host cell proteases: critical determinants of coronavirus tropism and pathogenesis. Virus Res 202:120-134

Miura TA, Travanty EA, Oko L, Bielefeldt-Ohmann H, Weiss SR, Beauchemin N, Holmes KV (2008) The spike glycoprotein of murine coronavirus MHV-JHM mediates receptorindependent infection and spread in the central nervous systems of Ceacam1a-/- Mice. J Virol 82:755-763

Molenkamp R, Spaan WJ (1997) Identification of a specific interaction between the coronavirus mouse hepatitis virus A59 nucleocapsid protein and packaging signal. Virology 239:78-86

Morales S, Parra B, Ramakrishna C, Blau DM, Stohlman SA (2001) B-cell-mediated lysis of cells infected with the neurotropic JHM strain of mouse hepatitis virus. Virology 286:160-167

Murray RS, Cai GY, Hoel K, Zhang JY, Soike KF, Cabirac GF (1992) Coronavirus infects and causes demyelination in primate central nervous system. Virology 188:274-284

Nagashima K, Wege H, Meyermann R, ter Meulen V (1978) Corona virus induced subacute demyelinating encephalomyelitis in rats: a morphological analysis. Acta Neuropathol 44:63-70

Nakagaki K, Nakagaki K, Taguchi F (2005) Receptor-independent spread of a highly neurotropic murine coronavirus JHMV strain from initially infected microglial cells in mixed neural cultures. J Virol 79:6102-6110

Narayanan K, Chen CJ, Maeda J, Makino S (2003) Nucleocapsid-independent specific viral RNA packaging via viral envelope protein and viral RNA signal. J Virol 77:2922-2927

Nash TC, Buchmeier MJ (1996) Spike glycoprotein-mediated fusion in biliary glycoproteinindependent cell-associated spread of mouse hepatitis virus infection. Virology 223:68-78

Nash TC, Buchmeier MJ (1997) Entry of mouse hepatitis virus into cells by endosomal and nonendosomal pathways. Virology 233:1-8

Navas S, Weiss SR (2003) Murine coronavirus-induced hepatitis: JHM genetic background eliminates A59 spike-determined hepatotropism. J Virol 77:4972-4978

Ontiveros E, Kim TS, Gallagher TM, Perlman S (2003) Enhanced virulence mediated by the murine coronavirus, mouse hepatitis virus strain JHM, is associated with a glycine at residue 310 of the spike glycoprotein. J Virol 77:10260-10269

Parker SE, Gallagher TM, Buchmeier MJ (1989) Sequence analysis reveals extensive polymorphism and evidence of deletions within the E2 glycoprotein gene of several strains of murine hepatitis virus. Virology 173:664-673

Parra B, Hinton DR, Marten NW, Bergmann CC, Lin MT, Yang CS, Stohlman SA (1999) IFNgamma is required for viral clearance from central nervous system oligodendroglia. J Immunol 162:1641-1647

Parra B, Lin MT, Stohlman SA, Bergmann CC, Atkinson R, Hinton DR (2000) Contributions of Fas-Fas ligand interactions to the pathogenesis of mouse hepatitis virus in the central nervous system. J Virol 74:2447-2450

Pearce BD, Hobbs MV, McGraw TS, Buchmeier MJ (1994) Cytokine induction during T-cellmediated clearance of mouse hepatitis virus from neurons in vivo. J Virol 68:5483-5495

Peiris JS, Guan Y, Yuen KY (2004) Severe acute respiratory syndrome. Nat Med 10:S88-S97

Peiris JS, Lai ST, Poon LL, Guan Y, Yam LY, Lim W, Nicholls J, Yee WK, Yan WW, Cheung MT et al (2003a) Coronavirus as a possible cause of severe acute respiratory syndrome. Lancet 361:1319-1325

Peiris JS, Yuen KY, Osterhaus AD, Stohr K (2003b) The severe acute respiratory syndrome. N Engl J Med 349:2431-2441

Perlman S, Pewe L (1998) Role of CTL mutants in demyelination induced by mouse hepatitis virus, strain JHM. Adv Exp Med Biol 440:515-519

Perlman S, Schelper R, Bolger E, Ries D (1987) Late onset, symptomatic, demyelinating encephalomyelitis in mice infected with MHV-JHM in the presence of maternal antibody. Microb Pathog 2:185-194

Pewe L, Haring J, Perlman S (2002) CD4 T-cell-mediated demyelination is increased in the absence of gamma interferon in mice infected with mouse hepatitis virus. J Virol 76:7329-7333 
Pewe L, Perlman S (2002) Cutting edge: CD8 T cell-mediated demyelination is IFN-gamma dependent in mice infected with a neurotropic coronavirus. J Immunol 168:1547-1551

Pewe L, Wu GF, Barnett EM, Castro RF, Perlman S (1996) Cytotoxic T cell-resistant variants are selected in a virus-induced demyelinating disease. Immunity 5:253-262

Pewe L, Xue S, Perlman S (1998) Infection with cytotoxic T-lymphocyte escape mutants results in increased mortality and growth retardation in mice infected with a neurotropic coronavirus. J Virol 72:5912-5918

Pewe L, Zhou H, Netland J, Tangudu C, Olivares H, Shi L, Look D, Gallagher T, Perlman S (2005) A severe acute respiratory syndrome-associated coronavirus-specific protein enhances virulence of an attenuated murine coronavirus. J Virol 79:11335-11342

Phares TW, Stohlman SA, Hinton DR, Bergmann CC (2012a) Enhanced CD8 T-cell anti-viral function and clinical disease in B7-H1-deficient mice requires CD4 T cells during encephalomyelitis. J Neuroinflammation 9:269

Phares TW, Stohlman SA, Hwang M, Min B, Hinton DR, Bergmann CC (2012b) CD4 T cells promote $\mathrm{CD} 8 \mathrm{~T}$ cell immunity at the priming and effector site during viral encephalitis. J Virol 86:2416-2427

Phillips JJ, Chua MM, Lavi E, Weiss SR (1999) Pathogenesis of chimeric MHV4/MHV-A59 recombinant viruses: the murine coronavirus spike protein is a major determinant of neurovirulence. J Virol 73:7752-7760

Phillips JJ, Chua MM, Rall GF, Weiss SR (2002) Murine coronavirus spike glycoprotein mediates degree of viral spread, inflammation, and virus-induced immunopathology in the central nervous system. Virology 301:109-120

Raj VS, Mou H, Smits SL, Dekkers DH, Muller MA, Dijkman R, Muth D, Demmers JA, Zaki A, Fouchier RA et al (2013) Dipeptidyl peptidase 4 is a functional receptor for the emerging human coronavirus-EMC. Nature 495:251-254

Ramakrishna C, Bergmann CC, Holmes KV, Stohlman SA (2004) Expression of the mouse hepatitis virus receptor by central nervous system microglia. J Virol 78:7828-7832

Ramakrishna C, Stohlman SA, Atkinson RD, Shlomchik MJ, Bergmann CC (2002) Mechanisms of central nervous system viral persistence: the critical role of antibody and B cells. J Immunol 168:1204-1211

Ransohoff RM, Engelhardt B (2012) The anatomical and cellular basis of immune surveillance in the central nervous system. Nat Rev Immunol 12:623-635

Ransohoff RM, Kivisakk P, Kidd G (2003) Three or more routes for leukocyte migration into the central nervous system. Nat Rev Immunol 3:569-581

Rempel JD, Murray SJ, Meisner J, Buchmeier MJ (2004) Differential regulation of innate and adaptive immune responses in viral encephalitis. Virology 318:381-392

Roth-Cross JK, Bender SJ, Weiss SR (2008) Murine coronavirus mouse hepatitis virus is recognized by MDA5 and induces type I interferon in brain macrophages/microglia. J Virol 82:9829-9838

Rowe CL, Baker SC, Nathan MJ, Fleming JO (1997) Evolution of mouse hepatitis virus: detection and characterization of spike deletion variants during persistent infection. J Virol 71:2959-2969

Sawicki SG, Sawicki DL, Siddell SG (2007) A contemporary view of coronavirus transcription. J Virol 81:20-29

Schaecher SR, Mackenzie JM, Pekosz A (2007) The ORF7b protein of severe acute respiratory syndrome coronavirus (SARS-CoV) is expressed in virus-infected cells and incorporated into SARS-CoV particles. J Virol 81:718-731

Schickli JH, Thackray LB, Sawicki SG, Holmes KV (2004) The N-terminal region of the murine coronavirus spike glycoprotein is associated with the extended host range of viruses from persistently infected murine cells. J Virol 78:9073-9083

Schickli JH, Zelus BD, Wentworth DE, Sawicki SG, Holmes KV (1997) The murine coronavirus mouse hepatitis virus strain A59 from persistently infected murine cells exhibits an extended host range. J Virol 71:9499-9507 
Schwarz B, Routledge E, Siddell SG (1990) Murine coronavirus nonstructural protein ns2 is not essential for virus replication in transformed cells. J Virol 64:4784-4791

Schwender S, Imrich H, Dorries R (1991) The pathogenic role of virus-specific antibody-secreting cells in the central nervous system of rats with different susceptibility to coronavirus-induced demyelinating encephalitis. Immunology 74:533-538

Shi ST, Lai MM (2005) Viral and cellular proteins involved in coronavirus replication. Curr Top Microbiol Immunol 287:95-131

Shirato K, Momotani E, Takata M, Sekikawa K, Taniguchi T (2008) Tumor necrosis factor alpha is not a pathogenic determinant in acute lethal encephalitis induced by a highly neurovirulent strain of mouse hepatitis virus. Arch Virol 153:549-553

Snijder EJ, Bredenbeek PJ, Dobbe JC, Thiel V, Ziebuhr J, Poon LL, Guan Y, Rozanov M, Spaan WJ, Gorbalenya AE (2003) Unique and conserved features of genome and proteome of SARScoronavirus, an early split-off from the coronavirus group 2 lineage. J Mol Biol 331:991-1004

Sorensen O, Perry D, Dales S (1980) In vivo and in vitro models of demyelinating diseases. III. JHM virus infection of rats. Arch Neurol 37:478-484

Sperry SM, Kazi L, Graham RL, Baric RS, Weiss SR, Denison MR (2005) Single-amino-acid substitutions in open reading frame (ORF) 1b-nsp14 and ORF 2a proteins of the coronavirus mouse hepatitis virus are attenuating in mice. J Virol 79:3391-3400

Stohlman SA, Bergmann CC, Lin MT, Cua DJ, Hinton DR (1998) CTL effector function within the central nervous system requires CD4+ T cells. J Immunol 160:2896-2904

Stohlman SA, Hinton DR, Cua D, Dimacali E, Sensintaffar J, Hofman FM, Tahara SM, Yao Q (1995) Tumor necrosis factor expression during mouse hepatitis virus-induced demyelinating encephalomyelitis. J Virol 69:5898-5903

Stohlman SA, Matsushima GK, Casteel N, Weiner LP (1986) In vivo effects of coronavirusspecific T cell clones: DTH inducer cells prevent a lethal infection but do not inhibit virus replication. J Immunol 136:3052-3056

Stohlman SA, Sussman MA, Matsushima GK, Shubin RA, Erlich SS (1988) Delayed-type hypersensitivity response in the central nervous system during JHM virus infection requires viral specificity for protection. J Neuroimmunol 19:255-268

Sun N, Perlman S (1995) Spread of a neurotropic coronavirus to spinal cord white matter via neurons and astrocytes. J Virol 69:633-641

Sutherland RM, Chua MM, Lavi E, Weiss SR, Paterson Y (1997) CD4+ and CD8+ T cells are not major effectors of mouse hepatitis virus A59-induced demyelinating disease. J Neurovirol 3:225-228

Suzuki H, Taguchi F (1996) Analysis of the receptor-binding site of murine coronavirus spike protein. J Virol 70:2632-2636

Taguchi F, Kubo H, Takahashi H, Suzuki H (1995) Localization of neurovirulence determinant for rats on the S1 subunit of murine coronavirus JHMV. Virology 208:67-74

Taguchi F, Siddell SG, Wege H, ter Meulen V (1985) Characterization of a variant virus selected in rat brains after infection by coronavirus mouse hepatitis virus JHM. J Virol 54:429-435

Templeton SP, Kim TS, O'Malley K, Perlman S (2008) Maturation and localization of macrophages and microglia during infection with a neurotropic murine coronavirus. Brain Pathol $18: 40-51$

Thackray LB, Holmes KV (2004) Amino acid substitutions and an insertion in the spike glycoprotein extend the host range of the murine coronavirus MHV-A59. Virology 324:510-524

Tran EH, Prince EN, Owens T (2000) IFN-gamma shapes immune invasion of the central nervous system via regulation of chemokines. J Immunol 164:2759-2768

Trandem K, Anghelina D, Zhao J, Perlman S (2010) Regulatory T cells inhibit T cell proliferation and decrease demyelination in mice chronically infected with a coronavirus. J Immunol 184:4391-4400

Trapp BD, Peterson J, Ransohoff RM, Rudick R, Mork S, Bo L (1998) Axonal transection in the lesions of multiple sclerosis. N Engl J Med 338:278-285 
Trifilo MJ, Bergmann CC, Kuziel WA, Lane TE (2003) CC chemokine ligand 3 (CCL3) regulates CD8(+)-T-cell effector function and migration following viral infection. J Virol 77:4004-4014

Trifilo MJ, Montalto-Morrison C, Stiles LN, Hurst KR, Hardison JL, Manning JE, Masters PS, Lane TE (2004) CXC chemokine ligand 10 controls viral infection in the central nervous system: evidence for a role in innate immune response through recruitment and activation of natural killer cells. J Virol 78:585-594

Trujillo JA, Fleming EL, Perlman S (2013) Transgenic CCL2 expression in the central nervous system results in a dysregulated immune response and enhanced lethality after coronavirus infection. J Virol 87:2376-2389

Turner BC, Hemmila EM, Beauchemin N, Holmes KV (2004) Receptor-dependent coronavirus infection of dendritic cells. J Virol 78:5486-5490

van der Veen RC (1996) Immunogenicity of JHM virus proteins: characterization of a CD4+ T cell epitope on nucleocapsid protein which induces different T-helper cell subsets. Virology 225:339-346

Vennema H, Godeke GJ, Rossen JW, Voorhout WF, Horzinek MC, Opstelten DJ, Rottier PJ (1996) Nucleocapsid-independent assembly of coronavirus-like particles by co-expression of viral envelope protein genes. EMBO J 15:2020-2028

Versteeg GA, Bredenbeek PJ, van den Worm SH, Spaan WJ (2007) Group 2 coronaviruses prevent immediate early interferon induction by protection of viral RNA from host cell recognition. Virology 361:18-26

Vijgen L, Keyaerts E, Moes E, Thoelen I, Wollants E, Lemey P, Vandamme AM, Van Ranst M (2005) Complete genomic sequence of human coronavirus OC43: molecular clock analysis suggests a relatively recent zoonotic coronavirus transmission event. J Virol 79:1595-1604

Vlasak R, Luytjes W, Leider J, Spaan W, Palese P (1988a) The E3 protein of bovine coronavirus is a receptor-destroying enzyme with acetylesterase activity. J Virol 62:4686-4690

Vlasak R, Luytjes W, Spaan W, Palese P (1988b) Human and bovine coronaviruses recognize sialic acid-containing receptors similar to those of influenza C viruses. Proc Natl Acad Sci U S A 85:4526-4529

Wang FI, Fleming JO, Lai MM (1992a) Sequence analysis of the spike protein gene of murine coronavirus variants: study of genetic sites affecting neuropathogenicity. Virology $186: 742-749$

Wang FI, Hinton DR, Gilmore W, Trousdale MD, Fleming JO (1992b) Sequential infection of glial cells by the murine hepatitis virus JHM strain (MHV-4) leads to a characteristic distribution of demyelination. Lab Invest 66:744-754

Wang FI, Stohlman SA, Fleming JO (1990) Demyelination induced by murine hepatitis virus JHM strain (MHV-4) is immunologically mediated. J Neuroimmunol 30:31-41

Wang Q, Qi J, Yuan Y, Xuan Y, Han P, Wan Y, Ji W, Li Y, Wu Y, Wang J et al (2014) Bat origins of MERS-CoV supported by bat coronavirus HKU4 usage of human receptor CD26. Cell Host Microbe 16:328-337

Watanabe R, Wege H, ter Meulen V (1983) Adoptive transfer of EAE-like lesions from rats with coronavirus-induced demyelinating encephalomyelitis. Nature 305:150-153

Watanabe R, Wege H, ter Meulen V (1987) Comparative analysis of coronavirus JHM-induced demyelinating encephalomyelitis in Lewis and Brown Norway rats. Lab Invest 57:375-384

Weiner LP (1973) Pathogenesis of demyelination induced by a mouse hepatitis. Arch Neurol 28:298-303

Weiner LP, Johnson RT, Herndon RM (1973) Viral infections and demyelinating diseases. N Engl J Med 288:1103-1110

Weiss SR, Leibowitz JL (2011) Coronavirus pathogenesis. Adv Virus Res 81:85-164

Wijburg OL, Heemskerk MH, Sanders A, Boog CJ, Van Rooijen N (1996) Role of virus-specific $\mathrm{CD} 4+$ cytotoxic $\mathrm{T}$ cells in recovery from mouse hepatitis virus infection. Immunology $87: 34-41$

Williams RK, Jiang GS, Holmes KV (1991) Receptor for mouse hepatitis virus is a member of the carcinoembryonic antigen family of glycoproteins. Proc Natl Acad Sci U S A 88:5533-5536 
Williamson JS, Stohlman SA (1990) Effective clearance of mouse hepatitis virus from the central nervous system requires both CD4+ and CD8+ T cells. J Virol 64:4589-4592

Williamson JS, Sykes KC, Stohlman SA (1991) Characterization of brain-infiltrating mononuclear cells during infection with mouse hepatitis virus strain JHM. J Neuroimmunol 32:199-207

Wilson L, Gage P, Ewart G (2006) Hexamethylene amiloride blocks E protein ion channels and inhibits coronavirus replication. Virology 353:294-306

Wu GF, Dandekar AA, Pewe L, Perlman S (2000a) CD4 and CD8 T cells have redundant but not identical roles in virus-induced demyelination. J Immunol 165:2278-2286

Wu GF, Perlman S (1999) Macrophage infiltration, but not apoptosis, is correlated with immunemediated demyelination following murine infection with a neurotropic coronavirus. J Virol 73:8771-8780

Wu GF, Pewe L, Perlman S (2000b) Coronavirus-induced demyelination occurs in the absence of inducible nitric oxide synthase. J Virol 74:7683-7686

Xue S, Perlman S (1997) Antigen specificity of CD4 T cell response in the central nervous system of mice infected with mouse hepatitis virus. Virology 238:68-78

Xue S, Sun N, Van Rooijen N, Perlman S (1999) Depletion of blood-borne macrophages does not reduce demyelination in mice infected with a neurotropic coronavirus. J Virol 73:6327-6334

Yamaguchi K, Goto N, Kyuwa S, Hayami M, Toyoda Y (1991) Protection of mice from a lethal coronavirus infection in the central nervous system by adoptive transfer of virus-specific $\mathrm{T}$ cell clones. J Neuroimmunol 32:1-9

Ye Y, Hauns K, Langland JO, Jacobs BL, Hogue BG (2007) Mouse hepatitis coronavirus A59 nucleocapsid protein is a type I interferon antagonist. J Virol 81:2554-2563

Yong VW, Power C, Forsyth P, Edwards DR (2001) Metalloproteinases in biology and pathology of the nervous system. Nat Rev Neurosci 2:502-511

Yu X, Bi W, Weiss SR, Leibowitz JL (1994) Mouse hepatitis virus gene 5b protein is a new virion envelope protein. Virology 202:1018-1023

Zaki AM, van Boheemen S, Bestebroer TM, Osterhaus AD, Fouchier RA (2012) Isolation of a novel coronavirus from a man with pneumonia in Saudi Arabia. $N$ Engl J Med 367:1814-1820

Zhao J, Zhao J, Perlman S (2009) De novo recruitment of antigen-experienced and naive T cells contributes to the long-term maintenance of antiviral $\mathrm{T}$ cell populations in the persistently infected central nervous system. J Immunol 183:5163-5170

Zhao J, Zhao J, Perlman S (2014) Virus-specific regulatory T cells ameliorate encephalitis by repressing effector T cell functions from priming to effector stages. PLoS Pathog 10:e1004279

Zhao L, Jha BK, Wu A, Elliott R, Ziebuhr J, Gorbalenya AE, Silverman RH, Weiss SR (2012) Antagonism of the interferon-induced OAS-RNase L pathway by murine coronavirus ns2 protein is required for virus replication and liver pathology. Cell Host Microbe 11:607-616

Zhou H, Perlman S (2007) Mouse hepatitis virus does not induce Beta interferon synthesis and does not inhibit its induction by double-stranded RNA. J Virol 81:568-574

Zhou J, Marten NW, Bergmann CC, Macklin WB, Hinton DR, Stohlman SA (2005) Expression of matrix metalloproteinases and their tissue inhibitor during viral encephalitis. J Virol 79:4764-4773

Zhou J, Stohlman SA, Atkinson R, Hinton DR, Marten NW (2002) Matrix metalloproteinase expression correlates with virulence following neurotropic mouse hepatitis virus infection. J Virol 76:7374-7384

Zhou J, Stohlman SA, Hinton DR, Marten NW (2003) Neutrophils promote mononuclear cell infiltration during viral-induced encephalitis. J Immunol 170:3331-3336

Ziebuhr J, Snijder EJ, Gorbalenya AE (2000) Virus-encoded proteinases and proteolytic processing in the Nidovirales. J Gen Virol 81:853-879 